\title{
Solar Corpuscular Radiation as a Heat Source of the Upper Atmosphere
}

\author{
by \\ G. Ishikawa \\ Meteorological Research Institute, Tokyo \\ (Received September 7, 1959)
}

\begin{abstract}
The heat production in the earth's upper atmosphere due to the collision between the air atoms and the solar corpuscular radiation is discussed. The fundamental processes are treated semi-classically to get approximate formulae for the quantitative discussion. The atmospheric model given by Miller is employed to get the numerical values of the atmospheric elements. The intensity and the energy spectra of solar corpuscular radiation at the top of the atmosphere are estimated from the recent rocket measurements. About sixty per cent of the total energy loss of primary radiation is transformed into thermal energy for the heating of the atmosphere. The vertical profile of the heating rate is sensitively affected by the energy spectra of the primary radiation.
\end{abstract}

\section{Introduction}

The energies which arrive at the earth from the outer space are divided into the two natural divisions-electromagnetic and corpuscular radiation, both of which mainly come from the sun. The electromagnetic radiation at normal incidence has a mean intensity of 2 calories per square centimeter per minute, or $1.395 \times 10^{6}$ ergs $\mathrm{cm}^{-2} \mathrm{sec}^{-1}$ or $8.790 \times 10^{17}$ ev $\mathrm{cm}^{-2} \mathrm{sec}^{-1}$, which is called the solar constant: The variation of the solar constant is not large and may not exceed the order of 2 per cent of change. The corpuscular radiation is on much more uncertain grounds.

Chapman (1954) discussed corpuscular influences upon the upper atmosphere in which the evidence for the corpuscular theory of magnetic storms and auroras is briefly reviewed.

KiEPENHEUER (1954) showed the reasons which favor the presence of corpuscular radiation in connection with the auroral phenomena.

(a) In a significant number of cases, a definite time interval exists between the occurrence of a great chromospheric flare and the beginning of a geomagnetic storm or of an auroral display. This time is of the order of a day and corresponds to a speed of travel from the sun to the earth of about $1600 \mathrm{~km} / \mathrm{sec}$.

(b) Except for the years of greatest sunspot activity, there is a definite positive correlation between the distribution of great long-lived prominences on the 
sun and geomagnetic activity. The latter is greatest three or four days after the passage of a great prominence through the central solar meridian.

(c) In certain types of auroras, there is an emission of strongly shifted hydrogen lines observed by MEINEL (1951) (especially the hydrogen alpha line) which, when interpreted in terms of Doppler shift, corresponds to a speed of approach to the earth of at least 2000 to $3000 \mathrm{~km} / \mathrm{sec}$. The above speeds are considerably higher than those concluded from the solar-terrestrial relationship. It must be assumed, as MARTYN (1951) proposes, that the solar corpuscles which actually penetrate to auroral heights undergo a kind of atter-acceleration in the vicinity of the earth.

(d) Certain spectroscopic observations, based upon an old proposal by CHAPMAN, indicate weak traces of strongly Doppler-shifted $\mathrm{Ca}^{+}$absorption lines. These absorption traces could be produced by solar corpuscular beams. There are, in addition, some anomalies in the radio frequency emission of active solar regions at wave lengths near one meter. Such irregularities might be interpreted in terms of absorption by a solar corpuscular beam.

(e) Generally, auroras occur only in polar latitudes. The distribution of auroras in frequency and intensity shows a definite symmetry when plotted in geomagnetic coordinates. Regardless of the fact that the Birkeland-Störmer theory cannot explain the formation of an aurora in detail, there can be no doubt that the trajectories of the auroral corpuscles are under the control of the magnetic field of the earth.

Pecker and Roberts (1955) made an extensive statistical research and gave a qualitative hypothesis that attributes recurrent "M-region" geomagnetic disturbances to the arrival at the earth of solar corpuscules, and also a related hypothesis associates non-recurrent magnetic storms with a different solar corpuscular source found in the active region of the sun.

In the Cross-Field Seminar on Possible Responses of Terrestrual Atmospheric Circulation to Changes in Solar Activity, June-July, 1956 held at High Altitude Observatory of the University of Colorado, the problems on corpuscular radiation were widely discussed.

The energy flux of corpuscular radiation at the top of the atmosphere is estimated by WARWICK as slightly more than one percent of the solar constant at the medium-size aurora, and a flux of the order of the solar constant may be quite possible near auroral zone at the unusual increase of solar activity. Hence, if this is the case, the solar corpuscules must be a very important heat source of the upper atmosphere in the limited region of the earth, since the corpuscular radiation loses its energy almost entirely in the topmost layer of the atmosphere, while the electromagnetic radiation as a whole is inefficiently absorbed in the same layer. However, the recent rockets and satellites data seem to indicate that the energy flux of corpuscular radiation of the order of $10^{4} \mathrm{erg} / \mathrm{cm}^{2} / \mathrm{sec}$ or more is rather overestimation. We shall come back to this point again in the later paragraph of this paper. Corpuscular radiation may include electrons, protons, heavier nuclei and neutral particles. It may be natural to assume, however, that the heavier nuclei and neutral particles comprise a minor ratio of corpuscular radiation. 
Most of the corpuscular radiation hitherto considered in connection with the theory of aurora, geomagnetic storm and cosmic-ray phenomena, is a beam or a gas cloud of an electrically neutral mixture of ions and electrons. (ChApman, S. and Ferraro, V. C. A. 1931, 1932, 1933, BennetT, W. H., and Hulburt, E. O. 1954, Bennett, W. H. 1955, 1958, 1959, Alfven, H. 1939, 1940, 1955, Landseer-Jones, B. C. 1952, 1955, and SiNGER, S.F. 1957). The electromagnetic interaction between primary charged particles and the air atoms results in an excitation or an ionization of the atoms. As a consequence of the ionization, the electrons randomly ejected from the atoms become a primary source of heat production due to the passage of corpuscular radiation in the earth's atmosphere. Recombination and deexcitation, on the other hand, are considered to be the heat loss process. In this paper we make quantitative investigation of the heat production due to the collision between the air atoms and the primary charged particles of various energy ranges.

\section{Semi-classical expressions for the collision between a primary charged particle with atoms.}

In a low energy interaction, the primary particle loses its energy mainly by exciting or ionizing the atoms of the matter traversed. Since the quantum electrodynamics has not yet succeeded in formulating this problem at low energy regions in a completely rigorous manner, we resort here to semi-classical treatment and make a good approximation by referring to the experimental results hitherto made.

According to the recent rockets and satellites data, electrons seem to carry comparatively or more energy than that of protons in the topmost layer of the earth's atmosphere. We are not certain at present whether those electrons consist of the primary radiation or rather secondary ones. By a simple consideration of a neutral ionized stream assuemed in the Chapman-Ferraro theory of magnetic storm in which electrons and protons have about the same speed, the kinetic energy carried by electrons is by no means competitive with that of protons. From the Bennett theory of magnetically self-forcussing streams, the energy of electrons becomes even smaller than in the case of the Chapman-Ferraro theory. It might, however, be possible to get the energy flux of the same order for both protons and electrons by modifying such simple theories by taking account of some acceleration mechanism of charged particles near the earth.

In this section we shall limit ourselves to considering the case in which the primary particles are protons.

Let $M$ be the mass of the incident proton, $E$ its kinetic energy before the collision, $m$ the mass of an electron in the collided atom which is considered to be the target particle being initially at rest, $E^{\prime}$ the energy of the electron after collision. The principles of the conservation of energy and momentum give:

$$
E^{\prime}=4\left(\frac{m}{M}\right) E \cos ^{2} \theta
$$

where $\theta$ is the angle between the initial trajectory of the primary particle and the direction of motion of the electron after the collision. From the above equation the maximum transferable energy, $E^{\prime}{ }_{m}$, by a head-on collision becomes, 


$$
E^{\prime}{ }_{m}=4(m / M) E \text {, }
$$

we restrict our considerations to the case of small momentum transfers between the two particles, so that we may neglect the motion of the target particle during the interaction.

Let the positive $x$-axis be in the direction of motion of the incident particle and let $C_{\perp}$ be the component of its electric field normal to the direction of motion. Assuming that the primary particle is moving in the direction of increasing $x$ with velocity $v, C_{\perp}$ depends on the coordinate $x$ and on the time $t$ through a function of the form,

$$
\mathscr{C}_{\perp}=\mathscr{C}_{\perp}(x-v t) .
$$

From the symmetry properties of the field of a moving particle, the resultant momentum, $P^{\prime}$, acquired by the target particle during the collision is perpendicular to the direction of motion and has the magnitude,

$$
p^{\prime}=e \int_{-\infty}^{\infty} \mathscr{C}_{\perp}(x-v t) d t=\frac{e}{v} \int_{-\infty}^{\infty} \mathscr{C}_{\perp}(x-v t) d x
$$

Application of Gauss' theorem to the integral on the right-hand side in a cylinder with axis along the trajectory of the incident proton and radius equal to the impact parameter $b$ yields,

$$
2 \pi b \int_{-\infty}^{\infty} \mathscr{C}_{\perp}(x-v t) d x=4 \pi e .
$$

By combining equations (4) and (5) we get,

$$
p^{\prime}=\frac{2 e^{2}}{b v}
$$

or

$$
E^{\prime}=\frac{M e^{4}}{m b^{2} E} .
$$

The orbital electrons can be considered as free only if the collision time is short compared with their period of revolution. If otherwise, the electrons react adiabatically to the slowly varying field of the passing particle and do not absorb energy from its field. The interaction time, $\tau$, during which the value of the force is of the same order of magnitude as the maximum value, $e^{2} / b^{2}$, is reasonably defined as the time required for passing between the two points where the force is half of the maximum value. Thus we get,

$$
\tau=\frac{2 b}{v}=\sqrt{\frac{2 M}{E} \cdot b}
$$

considering that the relativistic correction is negligible for the particle heavier than proton and having an energy of less than a few million electron volt. Now the period of revolution of an orbital electron, $T_{n i}$, is written as,

$$
T_{n i}=\frac{2 \pi(\hbar n)^{3}}{\left(Z-S_{n i}\right)^{2} m e^{4}},
$$


where $n$ is the principal quantum number and $i$ indicates the state of each subshell, $Z$ is the atomic number of the target atom and $S_{n i}$ is the shielding constant for an ni-electron.

With the above consideration we get a condition from equations (8) and (9) for the electromagnetic interaction between an incident particle and an orbital electron to take place,

$$
\frac{\pi}{m} \sqrt{\frac{2 E}{M}} \frac{(\hbar n)^{3}}{\left(Z-S_{n i}\right)^{2} e^{4}} \geq b
$$

Further we have another condition from the energy consideration by means of equations (2) and (7),

$$
4\left(\frac{m}{M}\right) E \geq \frac{M e^{4}}{m b^{2} E}
$$

or

$$
b \geq \frac{M e^{2}}{2 m E}
$$

Since the left-hand side of equation (10) decreases with $E$ decreasing while the right-hand side of equation (11) increases with $E$ decreasing, the region in which $b$ can actually exist is a monotone increasing function of the primary energy, $E$. This means that there is a critical energy, below which an incident particle cannot interact electromagnetically with an $n i$-electron in the atom. Combining equations (10) and (11), we get the expression for the average critical energy, $E_{c i}$, as

$$
E_{c i}=\frac{M e^{4}\left(Z-S_{n i}\right)^{\frac{1}{3}}}{2 \pi^{\frac{2}{3}}(\hbar n)^{2}} .
$$

The values of $E_{c}$ for normal nitrogen $\left(1 s^{2} 2 s^{2} 2 p^{3}\right)$, oxygen $\left(1 s^{2} 2 s^{2} 2 p^{4}\right)$ and argon $\left(1 s^{2} 2 s^{2} 2 p^{6} 3 s^{2} 3 p^{6}\right)$ are calculated in case of an incident proton and are shown in Table 1 .

Table 1.

\begin{tabular}{ccccc}
\hline \hline Target atom & State & $E c(\mathrm{erg})$ & $E c(\mathrm{ev})$ & Velocity $\left(\mathrm{cm} \mathrm{sec}^{-1}\right)$ \\
\hline \multirow{2}{*}{ Nitrogen } & $1 s$ & $2.352 \times 10^{-7}$ & $1.468 \times 10^{5}$ & $5.304 \times 10^{8}$ \\
& $2 s, 2 p$ & $2.906 \times 10^{-8}$ & $1.814 \times 10^{4}$ & $1.864 \times 10^{8}$ \\
\hline \multirow{2}{*}{ Oxygen } & $1 s$ & $2.831 \times 10^{-7}$ & $1.767 \times 10^{5}$ & $5.819 \times 10^{8}$ \\
& $2 s, 2 p$ & $3.509 \times 10^{-8}$ & $2.244 \times 10^{4}$ & $2.049 \times 10^{8}$ \\
\hline \multirow{2}{*}{ Argon } & $1 s$ & $8.589 \times 10^{-7}$ & $5.362 \times 10^{5}$ & $1.014 \times 10^{9}$ \\
& $2 s, 2 p$ & $1.548 \times 10^{-7}$ & $9.665 \times 10^{4}$ & $4.303 \times 10^{8}$ \\
& $3 s, 3 p$ & $2.639 \times 10^{-8}$ & $1.647 \times 10^{4}$ & $1.777 \times 10^{8}$ \\
\hline
\end{tabular}

In this calculation we used the following rules for obtaining the average shielding constant for any group of electrons :

a) No contribution from any shell outside the one being considered. 
b) An amount 0.35 from each other electron in the same group considered except in the $1 s$ state where 0.30 is used instead.

c) If the shell considered is an $s$ or $p$ shell, an amount 0.85 is contributed from each other electron, with total quantum number less by one : and an amount 1.00 from each electron still further in.

d) If the shell is $d$ or $f$ shell, each electron in the groups closer in contributes 1.00 to the shielding constant.

The probability of a collision between an incident proton and $n i$-electrons with impact parameter in $d b$ at $b$ in a thickness of $d x \mathrm{gcm}^{-2}$ is given by,

$$
2 \pi b d b N\left(Z_{n i} / A\right) d x
$$

where $N$ is Avogadro's number, $Z_{n i}$ the number of $n i$-electrons of an atom of the material through which the incident particle travels, and $A$ is the corresponding mass number.

The probability of an energy transfer from the incident particle to $n i$-electrons in $d E^{\prime}$ at $E^{\prime}$ on traversal of a thickness $\mathrm{d} x$ of material is obtained by combining equations (7) and (13),

$$
\phi_{n i}\left(E^{\prime}\right) d E^{\prime} d x=\frac{\pi N Z_{n i} e^{4} M d E^{\prime} d x}{A m E E^{\prime 2}},
$$

where we put further restriction on $Z_{n i}$ that $E_{c i}$ must be smaller than $E$. For example, if $E \geq E_{c}$,

$$
Z_{1 s}=2, Z_{2 s}=2, Z_{2 p}=3, Z_{3 s}=0 \ldots \ldots
$$

for normal nitrogen,

$$
Z_{1 s}=2, Z_{2 s}=2, Z_{2 p}=4, Z_{3 s}=0 \cdots \cdots
$$

for normal oxygen, and

$$
Z_{1 s}=2, Z_{2 s}=2, Z_{2 p}=6, Z_{3 s}=2, Z_{3 p}=6, Z_{3 d}=0 \cdots \cdots
$$

for normal argon.

The expression for the probability of total energy transfer in $d E^{\prime}$ at $E^{\prime}$ in a unit thickness of material becomes,

$$
\phi\left(E^{\prime}\right) d E^{\prime}=\sum_{n i} \frac{\pi N Z_{n i} e^{4} M d E^{\prime}}{A m E E^{\prime 2}} .
$$

The summation must be carried out under the condition of $E \geq E_{c}$. The energy loss of the incident particle of energy $E$ on traversal of a unit thickness, $k_{n i}(E)$, is given by,

$$
k_{n i}(E)=\int_{E^{\prime} \min _{n i}}^{E_{\text {max }}^{\prime}} E^{\prime} \phi_{n i}\left(E^{\prime}\right) d E^{\prime},
$$

where 


$$
\begin{gathered}
E_{\text {max }}^{\prime}=4(m / M) E, \\
E_{n i}^{\prime} \min _{n i}=\frac{m M^{2} e^{12}\left(Z-S_{n i}\right)^{4}}{2 \pi^{2}(\hbar n)^{6} E^{2}},
\end{gathered}
$$

putting equations (15), (16) and (17) into the right-hand side of the above equation and integrating to obtain the following expression for $k_{n i}(E)$ :

$$
k_{n i}(E)=\frac{3 \pi N Z_{n i} e^{4} M}{A m E} \ln \left[\frac{2 \pi^{\frac{2}{3}}(\hbar n)^{2} E}{M e^{4}\left(Z-S_{n i}\right)^{\frac{4}{3}}}\right] .
$$

The total energy loss of the incident particle then becomes,

$$
k(E)=\sum_{\substack{n i \\\left(E \geq E_{c}\right)}} \frac{3 \pi N Z_{n i} e^{4} M}{A m E} \ln \left[\frac{2 \pi^{\frac{2}{3}}(\hbar n)^{2} E}{M e^{4}\left(Z-S_{n i}\right)^{\frac{4}{3}}}\right] .
$$

The summation must be carried out under the condition of $E \geq E_{n i}$.

Next we want to find the expression for the kinetic energy gain of liberated electrons in this electromagnetic interaction.

Let $k_{n i} *(E)$ be the kinetic energy gain per $\mathrm{gcm}^{-2}$ of liberated electrons from $n i$-state of the surrounding atoms resulting from the traversal of an incident particle of energy $E$, and $I_{n i}$ be the average energy required for ionizing the $n i$-electron from an atom of material, and we obtain,

where

$$
k_{n i} *(E)=\int_{I_{n i} \text { or } E^{\prime} \min _{n i}}^{E_{\max }^{\prime}} E^{\prime *} \phi_{n^{\prime}}\left(E^{\prime}\right) d E^{\prime},
$$

$$
E^{\prime *}=E^{\prime}-I,
$$

and the lower limit of integral must be either of the larger one of $I_{n i}$ or $E_{\text {min }}^{\prime}$ depending on the energy of incident particle.

The energy of an atom is $-\Sigma\left(\frac{Z-S_{n i}}{n}\right)^{2}$ in atomic unit, $\frac{m e^{4}}{2 \hbar^{2}}$. Hence the average ionizing energy $I_{n i}$ is calculated by taking difference of those two values of the above quantity; one is in normal state and the other corresponds to the case of one $n i$-electron removed.

In Table 2 are shown the calculated values of the average ionizing energy of various electrons and of the incident energy, $E_{n i}$, below which the minimum energy transfer, $E_{\min }^{\prime}$, becomes larger than $I_{n i}$. Thus the expression for $k_{n i}{ }^{*}(E)$ becomes,

$$
k_{n i}^{*}(E)=\frac{\pi N Z_{n i} e^{4} M}{A m E}\left[\eta_{n i}-\ln \eta_{n i}-1\right]
$$

where

$$
\eta_{n i}=I_{n i} / 4(m / M) E \quad \text { if } \quad I_{n i}>E_{n i}^{\prime} \min _{n i}
$$

or

$$
\eta_{n i}=E_{n i}^{\prime} \min _{n i} / 4(m / M) E \quad \text { if } \quad I_{n i}<E_{n i}^{\prime} \min _{n i}
$$


Table 2.

\begin{tabular}{|c|c|c|c|c|}
\hline Target atom & State & $I(\mathrm{erg})$ & $I(\mathrm{ev})$ & $E_{n i}$ (erg) \\
\hline \multirow{2}{*}{ Nitrogen } & $1 s$ & $6.845 \times 10^{-10}$ & 427.3 & $2.034 \times 10^{-7}$ \\
\hline & $2 s, 2 p$ & $2.060 \times 10^{-11}$ & 12.86 & $5.095 \times 10^{-8}$ \\
\hline \multirow{2}{*}{ Oxygen } & $1 s$ & $9.086 \times 10^{-10}$ & 567.2 & $2.332 \times 10^{-7}$ \\
\hline & $2 s, 2 p$ & $2.258 \times 10^{-11}$ & 14. 10 & $6.457 \times 10^{-8}$ \\
\hline Argon & $\begin{array}{c}1 s \\
2 s, 2 p \\
3 s, 3 p\end{array}$ & $\begin{array}{l}5.231 \times 10^{-9} \\
4.324 \times 10^{-10} \\
2.800 \times 10^{-11}\end{array}$ & $\begin{array}{c}3265.0 \\
269.9 \\
17.48\end{array}$ & $\begin{array}{l}5.136 \times 10^{-7} \\
1.367 \times 10^{-7} \\
3.782 \times 10^{-8}\end{array}$ \\
\hline
\end{tabular}

With those values $k_{n i}(E), k_{n i} *(E), k(E)$ and $k^{*}(E)$ are calculated for the case of nitrogen, oxygen, argon and air. The results thus obtained are shown in Fig. 1a-1g.

Knowing the composition of the atmosphere at any altitude, it is possible to determine the $k(E)$ and $k^{*}(E)$ values for the atmosphere. As abundant constituents of the atmosphere argon has also been considered besides nitrogen and oxygen, since in the lower ionospheric level it is comparable in abundance to molecular oxygen.

During the IGY period numbers of air sounding rockets and satellites were launched. These rockets and satellites have brought back data in the field of atmospheric structure, i. e. density, composition, temperature etc. It is to be emphasized, however, that only a part of the data is published at the present time and that the data presented are mostly preliminary. These data seem to indicate the existence of large variations in the structural elements which appear to be seasonal, diurnal and latitudinal. Also transient phenomena such as general circulation, solar eruption and the solar corpuscular emission itself could be significant factors in determining the structure of the upper atmosphere. In addition to the above, there seem to exist systematic differences between the observed values by different methods.

For example, as reported by Schilling and Sterne (1959), the atmospheric density obtained by satellite observations from some $180 \mathrm{~km}$ to $400 \mathrm{~km}$ altitude appears to be appreciably higher than was usually thought before satellite data became available. We are not in a position to judge those results at the present time, and hence we employed here tentatively the atmospheric model given by MiLler (1957) for our calculation.

Fig. 2 shows the altitude dependence of mixing ratios of nitrogen, oxygen and argon, regardless of their atomic or molecular type, calculated from the values given by MILLER.

Letting $r_{j}$ be the mixing ratio of $i$-constitutent in the air at a certain altitude, the energy loss of an incident particle of energy $E$ on traversal of a unit thickness of the air $k(E)$ is given by,

$$
k(E)=\sum_{j} \sum_{n i} r_{j} k_{j, n i}(E),
$$




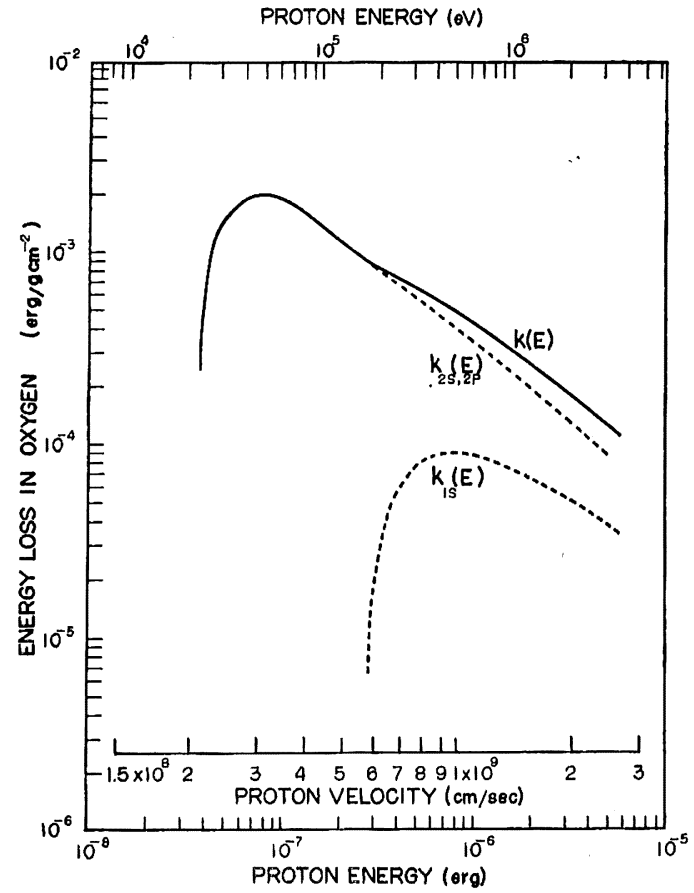

Fig. 1 (a)

PROTON ENERGY (eV)

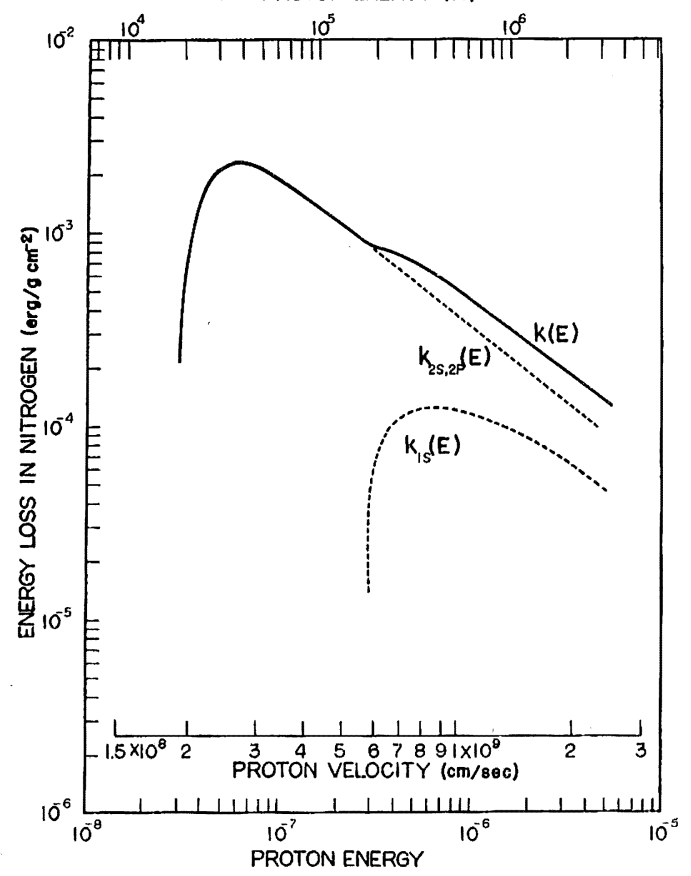

Fig. 1 (c)

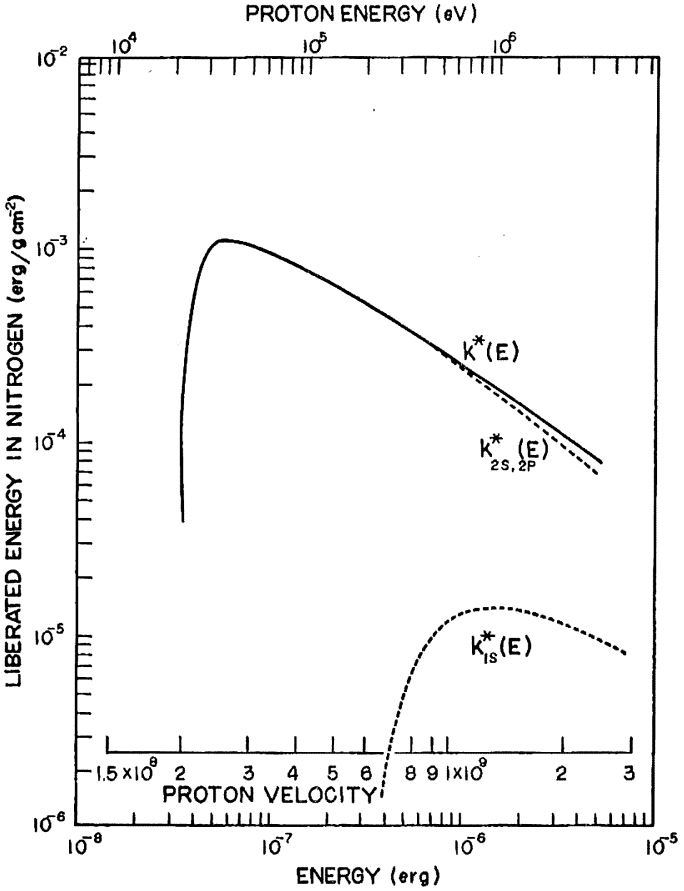

Fig. 1 (b)

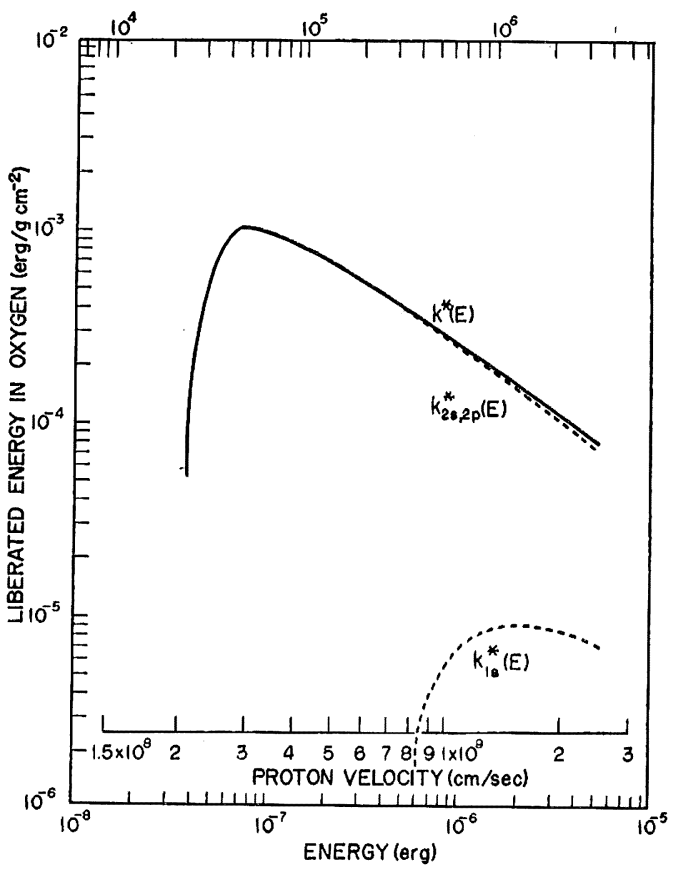

Fig. 1 (d) 


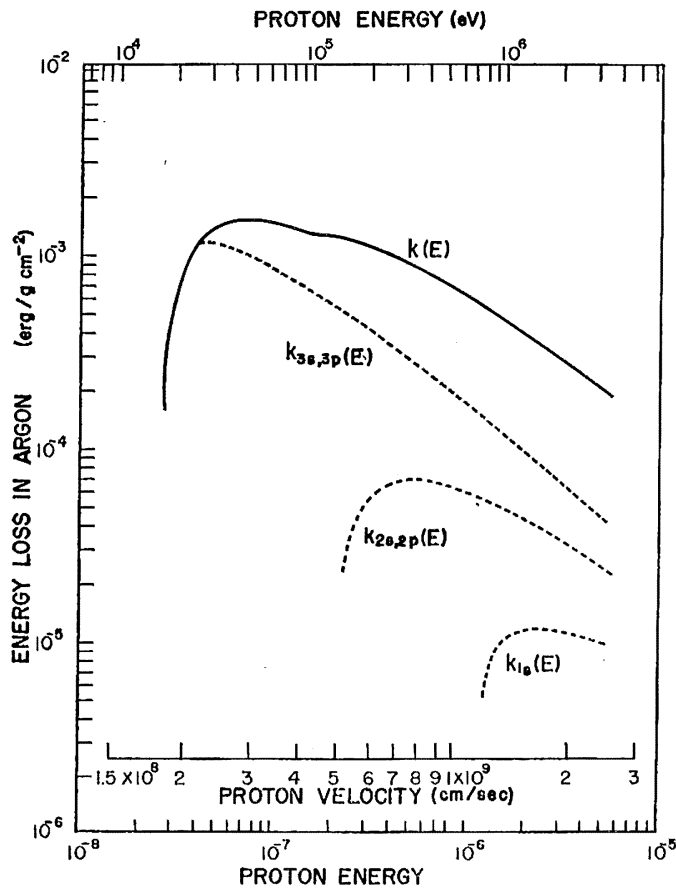

Fig. 1 (e)

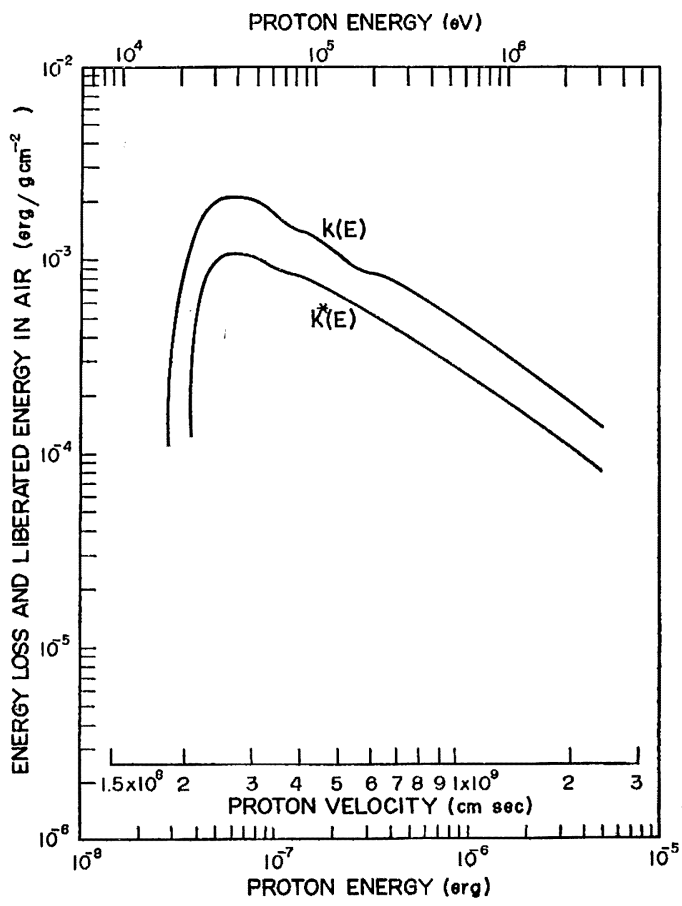

Fig. 1 (g)

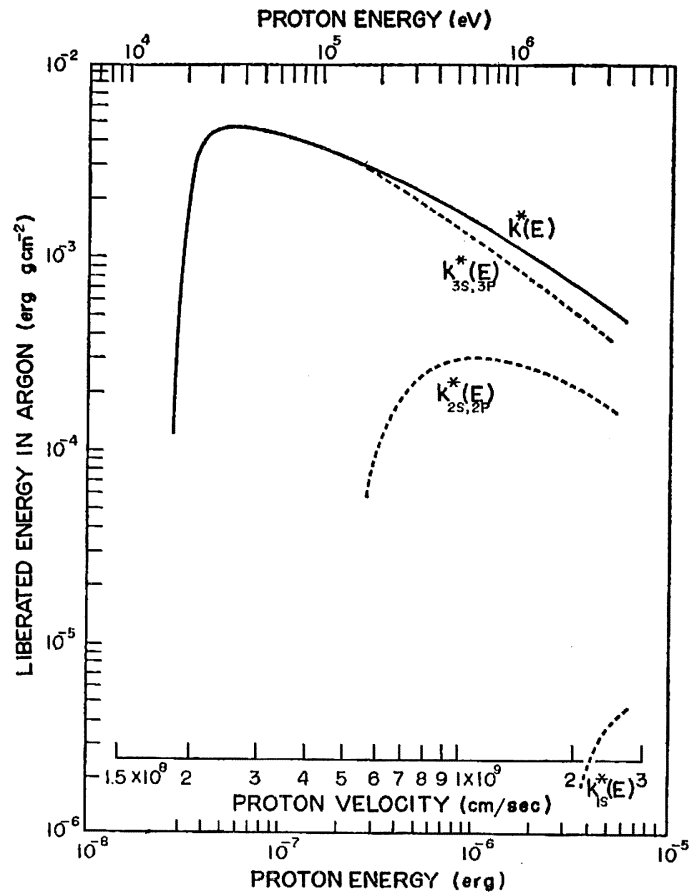

Fig. 1 (f)
Fig. 1. The total energy loss of incident particle on traversal of an unit thickness, $k(E)$, and the kinetic energy gain per $\mathrm{gcm}^{-2}$ of liberated electrons in various gases. 
Similarly the kinetic energy liberated in the surrounding air per $\mathrm{g} \mathrm{cm}^{-2}$ from an incident particle of energy $E$ becomes,

$$
k^{*}(E)=\sum_{j} \sum_{n i} r_{j} k^{*}{ }_{j, n i}(E) .
$$

The range $R$ of a primary particle of energy $E_{0}$ can be obtained in the following way :

\section{Putting}

$$
\Delta E_{i}=\delta E_{i-1},
$$

and

$$
\Delta x_{i}=\Delta E_{i} / k\left(E_{i}\right),
$$

we get

$$
R=\lim _{\delta \rightarrow 0} \sum_{i} \Delta x_{i}
$$

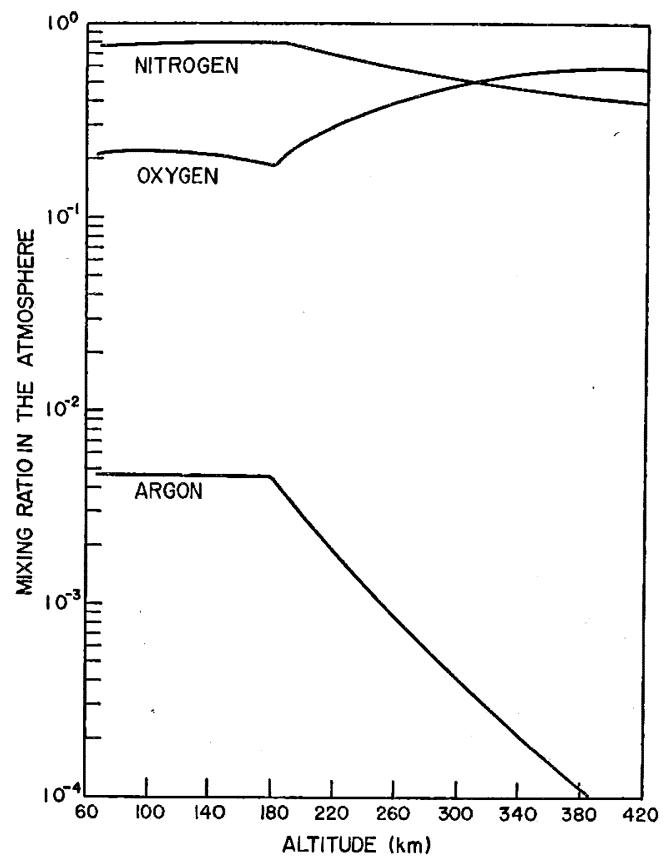

Fig. 2. The allitude dependence of mixing ratios of nitrogen, oxygen and argon, calculated from the values given by MiLLer.

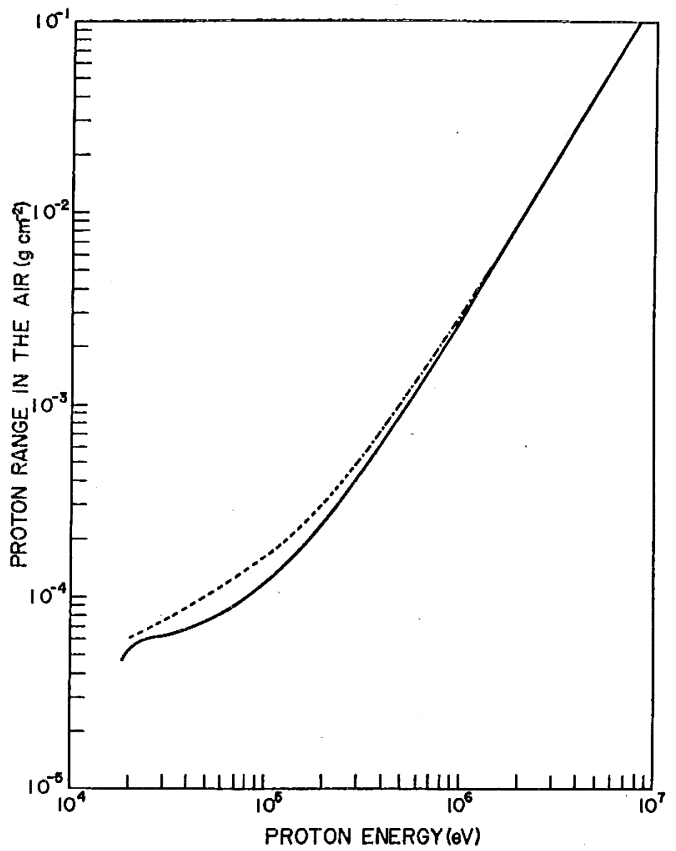

Fig. 3. The functional dependence of the range in air on the proton energy $E_{0}$.

The summation must be carried out under the condition of $E_{i} \geq E_{c}$, where $E_{c}$ is the smallest value of $E_{c i}$. In the actual numerical calculation $\delta$ cannot be taken to be an infinitesimally small number, and was taken to be $10^{-2}$.

The functional dependence of $R$ in air on the proton energy $E_{0}$ is illustrated in Fig. 3. The full line represents the result of our calculation using the equa- 
tions (26), (27) and (28), and the dashed line represents the results of experiment by C. J. Cook et al (1953). The dotted line represents the empirical range-energy relation in air for protons described in Experimental Nuclear Physics, Vol. 1, 1953 edited by E. SEgre.

In this figure we can see that our calculated range-energy relation is in good agreement with the results of experiments in this limited energy region.

\section{Dispersion of the energy of an incident particle.}

The quantity $k(E)$ defined as collision loss of an incident particle represents only an average value. Hence we have to know the dispersion of incident energy when we apply the above results to the actual problems.

Let us define $W\left(E_{0}, E, x\right) d E$ first as the probability that an incident particle of initial energy $E_{0}$ has an energy between $E$ and $E+d E$ after traversing a thickness of $x \mathrm{gcm}^{-2}$ of material. The function $W\left(E_{0}, E, x\right)$ satisfies the following equation:

$$
\begin{aligned}
\frac{\partial W\left(E_{0}, E, x\right)}{\partial x} & =\int_{0}^{\infty}\left[W\left(E_{0}, E+E^{\prime}, x\right) \phi\left(E+E^{\prime}, E^{\prime}\right)\right. \\
& \left.-W\left(E_{0}, E, x\right) \phi\left(E, E^{\prime}\right)\right] d E^{\prime},
\end{aligned}
$$

considering that $\phi\left(E, E^{\prime}\right)=0$ for $E^{\prime}>E_{\text {max }}^{\prime}$ and $W\left(E_{0}, E, x\right)=0$ for $E>E_{0}$.

Assume that the thickness of material traversed is sufficiently small so that the average energy loss is a small fraction of the initial energy and that the collision probability does not depend critically on the energy of incident particle. Then the average energy of an incident particle at depth $x$ may be very close to $E_{0}$ minus $K\left(E_{0}\right)$ times depth.

In the thin absorber defined above we easily see that $W\left(E_{0}, E, x\right)$ varies only slightly while $\phi\left(E, E^{\prime}\right)$ is appreciably different from zero. Hence we can expand $W\left(E_{0}, E+E^{\prime}, x\right)$ in a power series of $E^{\prime}$ about $E$ and neglect terms beyond the second order to get the approximate expression for the equation (29),

$$
\frac{\partial W\left(E_{0}, E, x\right)}{\partial x}=k(E) \frac{\partial W}{\partial E}+\frac{\sigma^{2}}{2} \frac{\partial^{2} W}{\partial E^{2}}
$$

where

$$
\sigma(E)=\left[\int_{0}^{\infty} E^{\prime 2} \phi\left(E, E^{\prime}\right) d E^{\prime}\right]^{\frac{1}{2}}
$$

Substituting $E_{0}$ for $E$ in $k$ and $\sigma$ we can solve the equation (30) to obtain,

$$
W\left(E_{0}, E, x\right)=\frac{1}{\sqrt{2 \pi \sigma^{2} x}} \exp \left[-\frac{(E-\langle E\rangle)^{2}}{2 \sigma^{2} x}\right]
$$

Thus the probability function $W\left(E_{0}, E, x\right)$ is a Gaussian function of $E$ with maximum at $\langle E(x)\rangle$. The width $\varepsilon(x)$ becomes,

$$
\varepsilon(x)=\sigma(E) \sqrt{x} .
$$


The conditions assumed in the above treatment are summerized as follows:

$$
\begin{gathered}
E_{0} \gg E_{0}-\langle E(x)\rangle=k\left(E_{0}\right) x \\
\phi\left(E+E^{\prime}, E^{\prime}\right)=\phi\left(E, E^{\prime}\right) \\
W\left(E_{0}, E+E^{\prime}, x\right)=W\left(E_{0}, E, x\right)+E \frac{\partial W}{\partial E}+\frac{E^{\prime 2}}{2} \frac{\partial^{2} W}{\partial E^{2}}
\end{gathered}
$$

$\sigma_{n i}(E)$ is calculated by means of equations (31) and (15), and the results obtained for the case of nitrogen and oxygen are shown in Fig. 4.

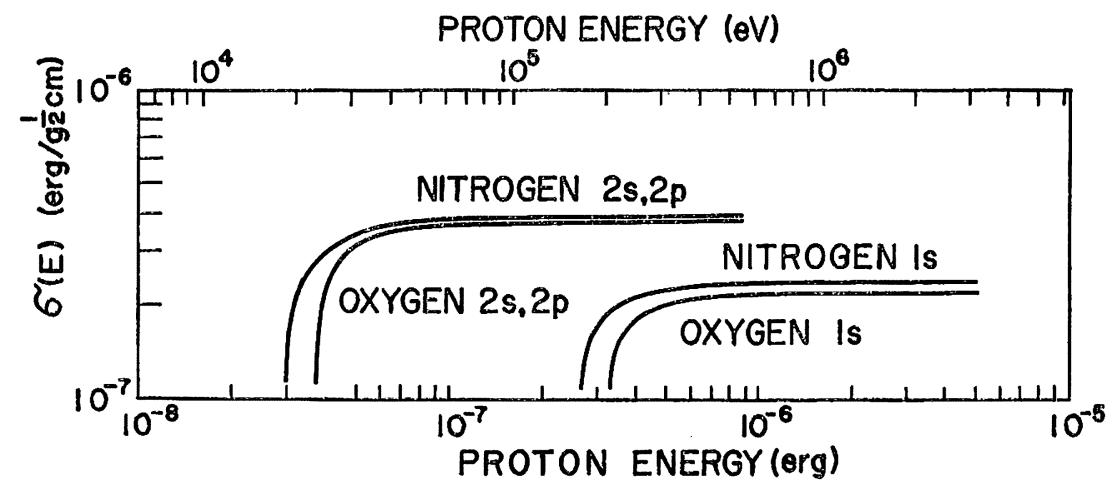

Fig. 4. Result of calculation of $\sigma(E)$ for the case of nitrogen and oxygen.

$\varepsilon(x)$ is also calculated for various incident energies. Figs. 5a and 5b show $\varepsilon(x) \mathrm{s}$ calculated by the equations (31) and (33) for the case of nitrogen and oxygen. We may neglect the contribution of the minor constituent, argon, in the calculation of the energy dispersion in this case, since $\sigma(E)$ which corresponds to the energy loss in close collision is, in general, much smaller than the total collision loss, $k(E)$.

To estimate the actual dispersion we take the following steps: first take a thin depth, $\Delta x_{0}$, with which all conditions (34), (35) and (36) are satisfied for the incident particle of energy $E_{0}$, and find the width $\varepsilon\left(E_{0}, \Delta x_{0}\right)$ by means of equations (31) and (33). Next choose another thin depth, $\Delta x_{1}$, also satisfying all the conditions (34), (35) and (36) for the particle of energy, $\left\langle E_{1}\right\rangle \equiv E_{0}-k\left(E_{0}\right) \cdot \Delta x_{0}$, and find the width $\varepsilon_{1}\left(\left\langle E_{1}\right\rangle, \Delta x_{1}\right)$. Similarly we can calculate the width $\varepsilon_{i}\left(\left\langle E_{i}\right\rangle, \Delta x_{i}\right)$ which corresponds to a thin depth $\Delta x_{i}$. Hence the quantity,

$$
\varepsilon^{*}\left(x_{j}\right)=\lim _{\Delta x_{i} \rightarrow 0} \sum_{i=0}^{j} \varepsilon_{i}\left(\left\langle E_{i}\right\rangle, \Delta x_{i}\right)
$$

is the dispersion of energy at the depth $x_{j}=\sum_{i=0}^{j} \Delta x_{i}$. In the actual procedure in our calculation, the number of the thin layers thus divided, for example in the case of $E_{0}=5 \times 10^{-6} \mathrm{erg}$, becomes about 500. In Figs. $6 \mathrm{a}$ and $6 \mathrm{~b}$ the calculated values of $\varepsilon^{*}(x)$ for various incident energies in the case of nitrogen and oxygen are shown. From these figures it is seen that the dispersion of energy is small compared with the energy of the incident particle in the energy range about $E_{c}$. 


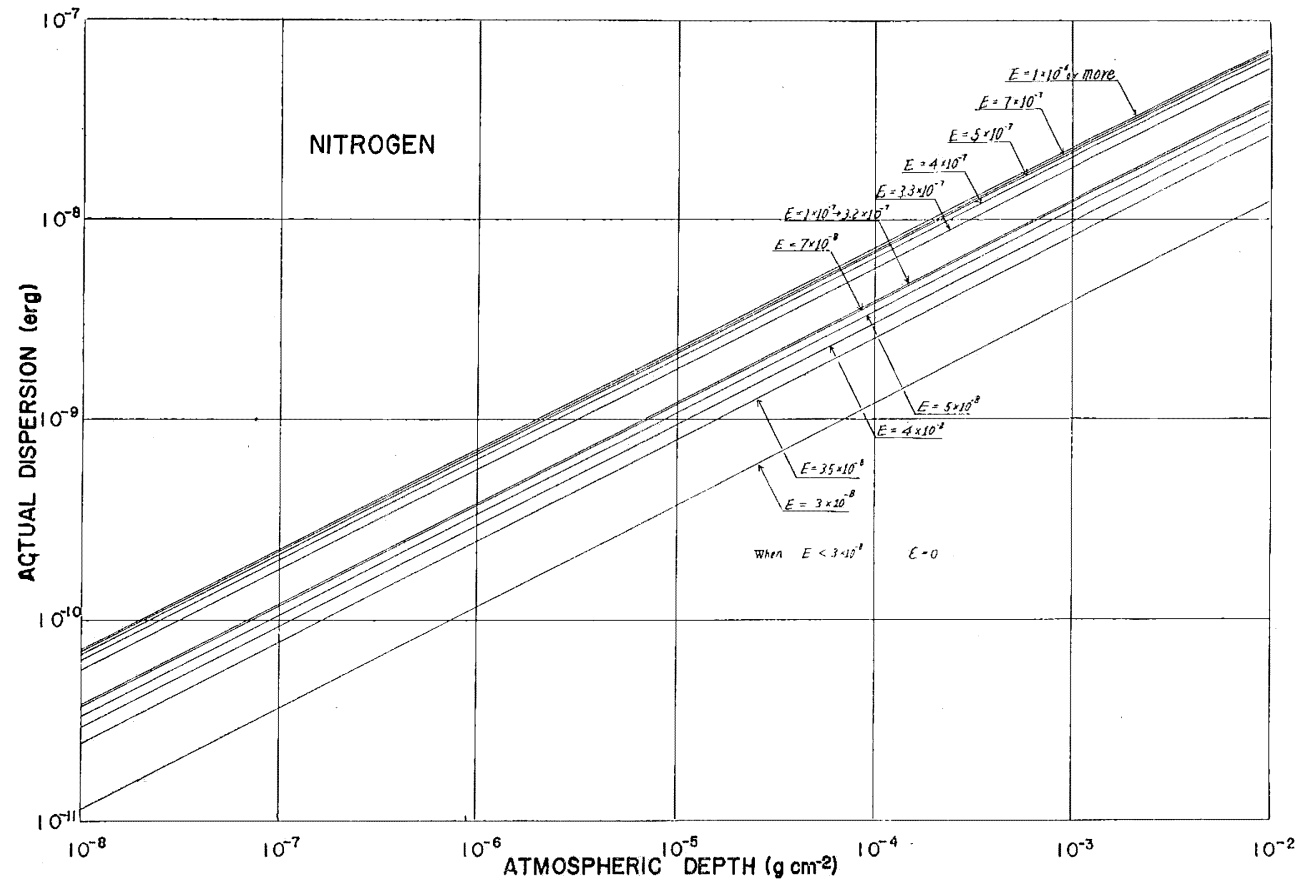

(a)

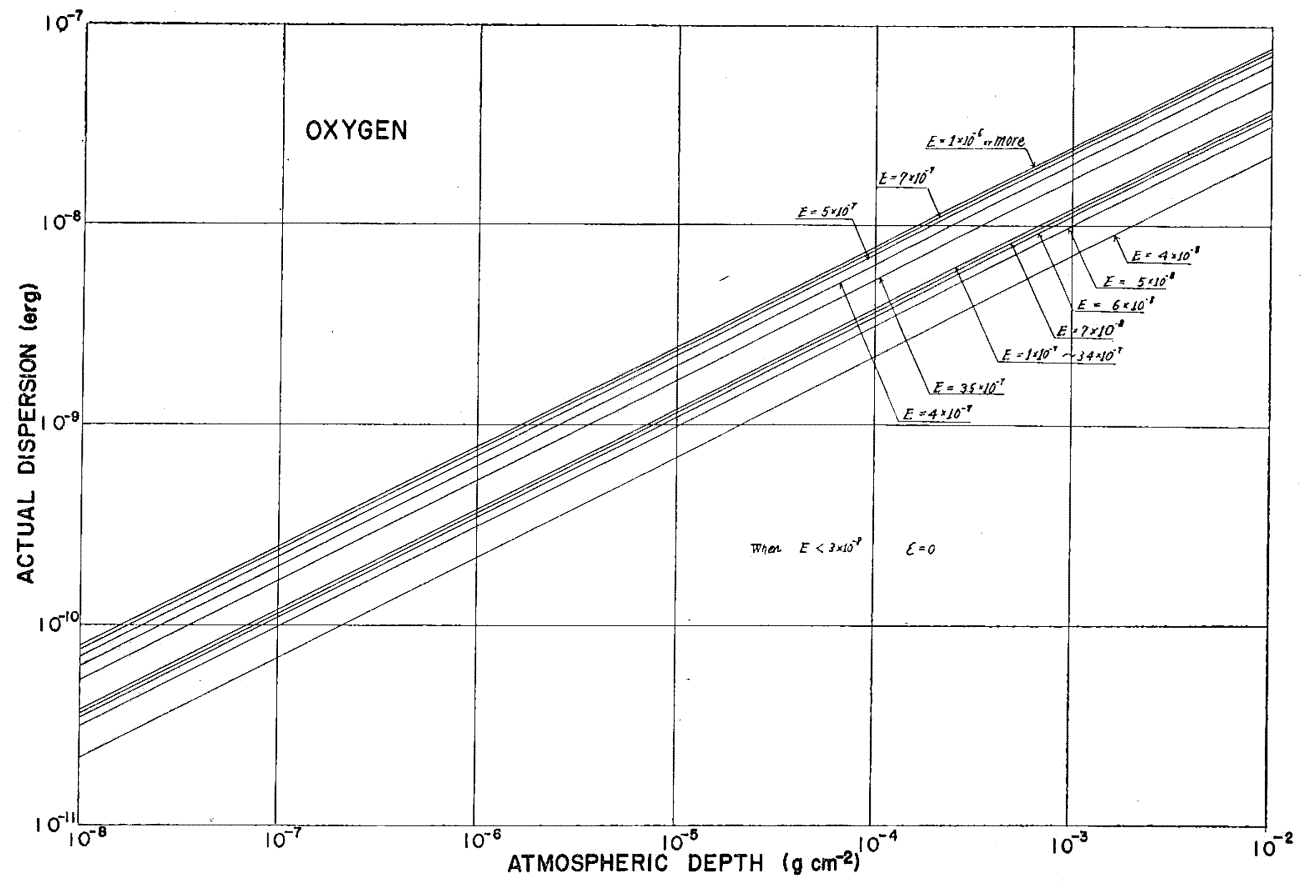

(b)

Fig. 5. The width $\varepsilon(x)$ for the case of nitrogen and oxygen. 


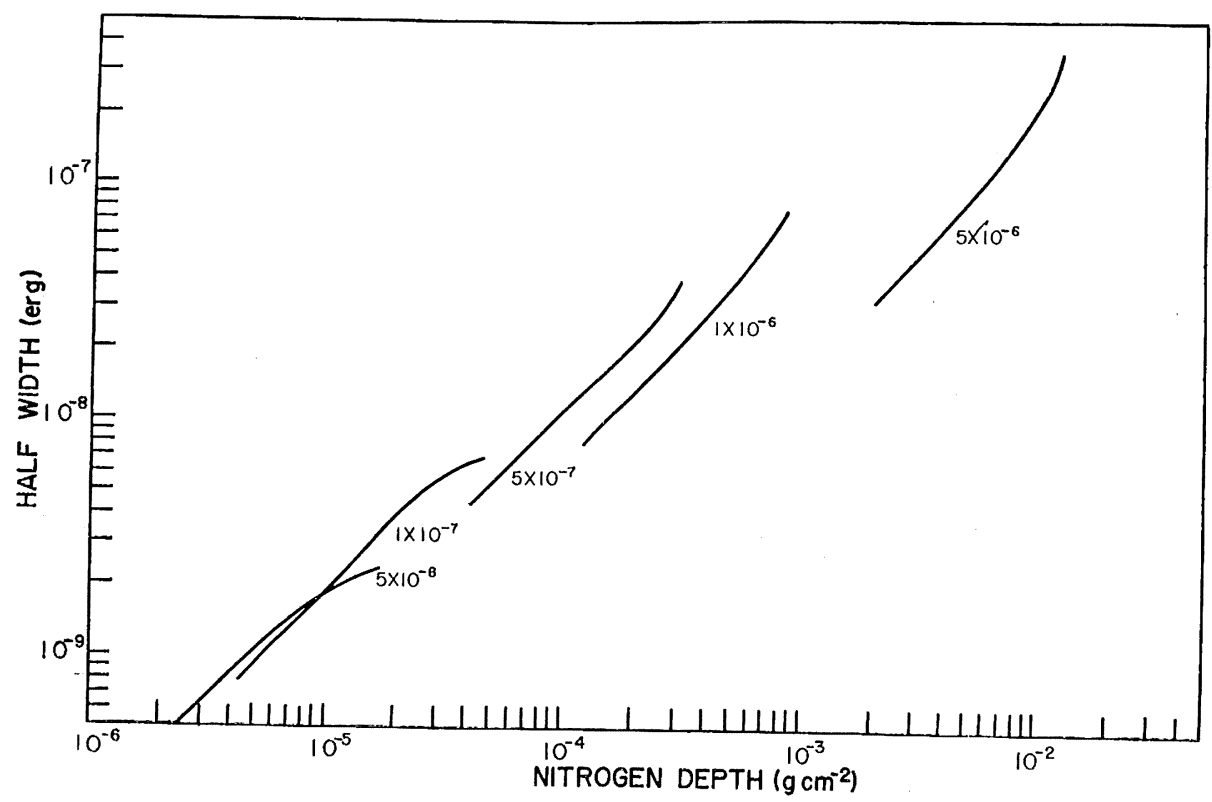

(a)

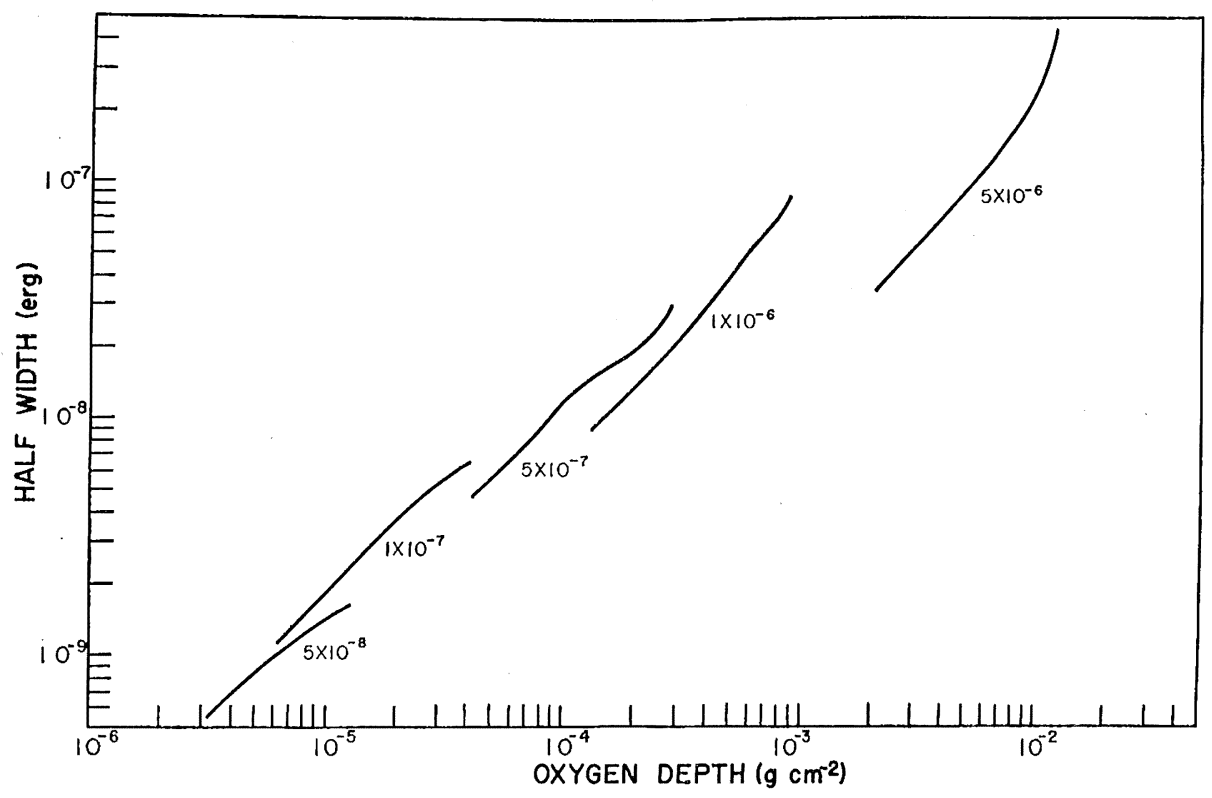

(b)

Fig. 6. The calculated values of $\varepsilon^{*}(x)$ for various incident energies in the case of nitrogen and oxygen. 


\section{Heat production by corpuscular radiation}

As shown in the previous section, the dispersion of the energy of a passing particle can be neglected for the first approximation, and consequently the average kinetic energy gain of surrounding air at a certain depth $x$ resulting trom a traversal of a charged particle, can be estimated in a similar way to that of finding rangeenergy relation.

Namely, the energy $E_{j}$ which a charged particle, having originally an energy of $E_{0}$, will have at a certain depth $x_{j}$ is determined by the equation,

$$
E_{j}=E_{0}-\sum_{i=0}^{j} \Delta E_{i}=E_{0}-\sum_{i=0}^{j} k\left(E_{i}\right) \Delta x_{i}
$$

Hence the average kinetic energy gain of surrounding air per $\mathrm{g} \mathrm{cm}^{-2}$ at a certain depth $x_{j}$ by the passing of this charged particle is determined by putting $E_{j}$ into equation (21).

Heat production at an atmospheric depth between $x$ and $x+d x$ resulting from a traversal of a charged particle originally having an energy of $E_{0}$ is given by,

$$
Q\left(E_{0}, x\right) d x=d x \sum_{n i} \int_{\substack{0 \\\left(E \geq E_{c}\right) \\ E_{0 i}}}^{k_{n i}} *(E) W\left(E_{0}, E, x\right) d E
$$

If the primary radiation has a differential energy spectrum $\phi\left(E_{0}\right) d E_{0}$ particles $\mathrm{cm}^{-2}$ $\sec ^{-1}$ at the top of the atmosphere, the heat production rate $d Q / d t$ becomes,

$$
\frac{d Q}{d t}=\int_{\substack{E_{c i} \\
n i}}^{\infty} d E_{0}\left\{\psi\left(E_{0}\right) \sum_{\substack{n i \\
\left(E \geq \int_{\begin{subarray}{c}{c \\
n i} }} \int_{0}^{E_{0}} k^{*}\right.}\end{subarray}}(E) W\left(E_{0}, E, x\right) d E\right\} .
$$

If we know the relation between the atmospheric depth and the altitude, the heat production and consequently the temperature increase at any level of height can be estimated. The relation between the atmospheric depth and the altitude is calculated from the pressure-altitude relation given by Miller. In this calculation the condition of hydrostatic equilibrium is assumed, which gives the relation between the atmospheric depth and the pressure as,

$$
x=\left(1+\frac{h}{R_{0}}\right)^{2} p(h) / g_{0}
$$

where $h$ and $R_{0}$ are, respectively, the height measured trom sea level and the radius of the earth, and $g_{0}$ is the acceleration of gravity at sea level having the value of $978.05 \mathrm{~cm} \mathrm{sec}^{-2}$. Fig. 7 shows the relation between the atmospheric depth, $x \mathrm{gcm}^{-2}$, and the altitude expressed in $\mathrm{km}$ thus obtained. The dashed curve above $600 \mathrm{~km}$ level is a simple extrapolation of the values given by MiLLER.

In Figs. $8 \mathrm{a}-8 \mathrm{~d}$ energy-depth relations of the proton primary in the individual constitutents of the air are shown. To estimate the temperature increase we have also to know the specific heat of the air at each level of height. The specific heat at constant pressure of $i$-element is given by the formula, 


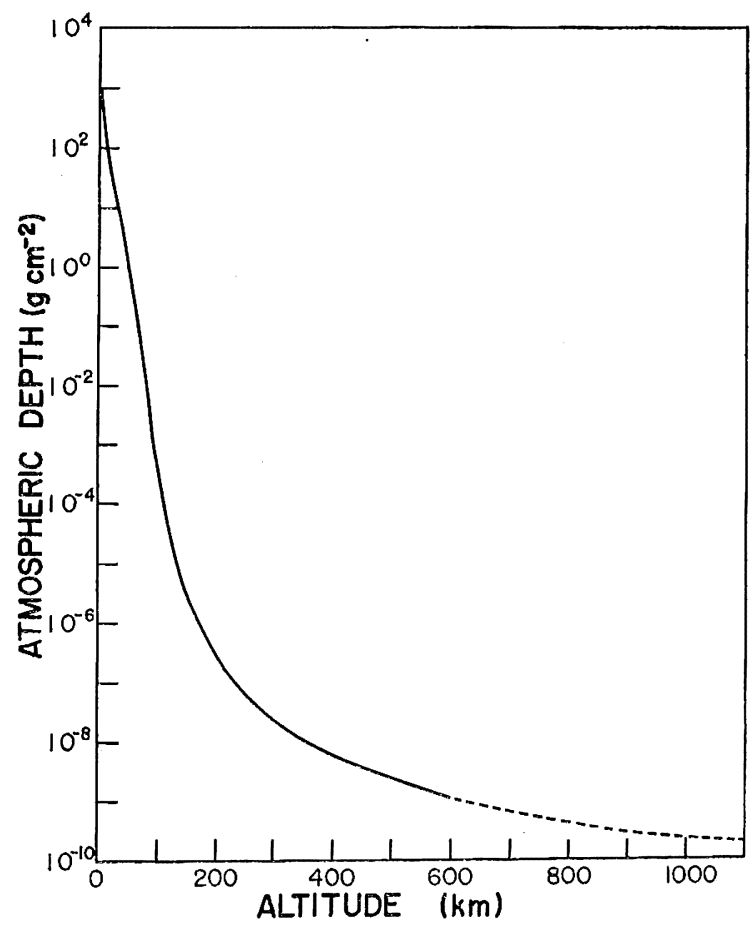

Fig. 7. Relation between the atmospheric depth, $\mathrm{g} \mathrm{cm}^{-2}$, and the altitude expressed in $\mathrm{km}$.

$$
C_{p, i}=S R_{i}
$$

where $S$ has the value of $5 / 2$ for atomic nitrogen, oxygen and argon, and has the value of $7 / 2$ for the molecular nitrogen and oxygen in so far as the temperature is not too high. $R_{i}$ can be written as

$$
R_{i}=1.0080 R_{0} / W_{i}
$$

where $R_{0}=8.31436 \times 10^{7} \mathrm{erg} \mathrm{mol}^{-1} \mathrm{deg}^{-1}$ is the Gas constant per mol and $W_{i}$ the molecular weight of $i$-element. In Table 3 the values for each element we used in the present research are shown.

Table 3.

\begin{tabular}{cccc}
\hline \hline Element & $W$ & $R$ & $\begin{array}{c}C_{p} \\
\left(\mathrm{cal} \mathrm{g}^{-1} \mathrm{deg}^{-1}\right)\end{array}$ \\
\hline$N$ & 14.008 & $5.983 \times 10^{6}$ & 0.3573 \\
$O$ & 16.000 & $5.238 \times 10^{6}$ & 0.3128 \\
$N_{2}$ & 28.016 & $2.991 \times 10^{6}$ & 0.2501 \\
$O_{2}$ & 32.000 & $2.619 \times 10^{6}$ & 0.2190 \\
$A$ & 39.944 & $2.098 \times 10^{6}$ & 0.1253 \\
\hline
\end{tabular}

Hence the average specific heart of the air $\bar{C}_{p}(h)$ can be written as 


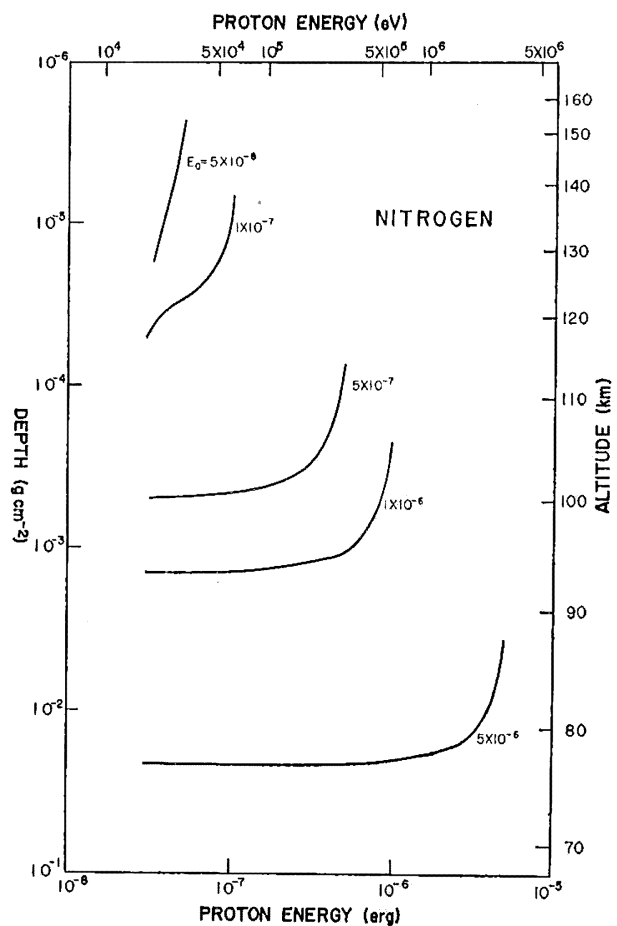

(a)

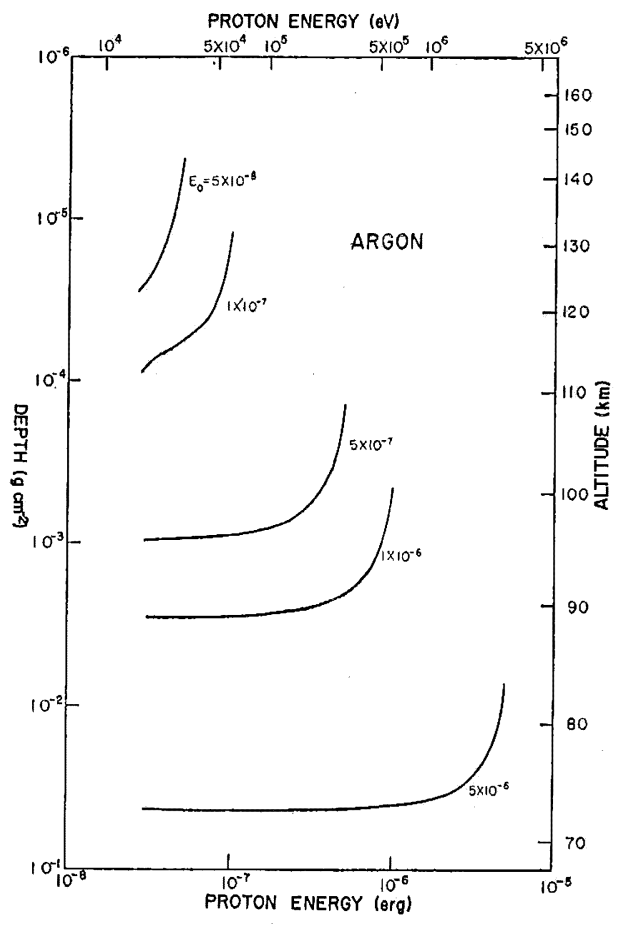

(c)

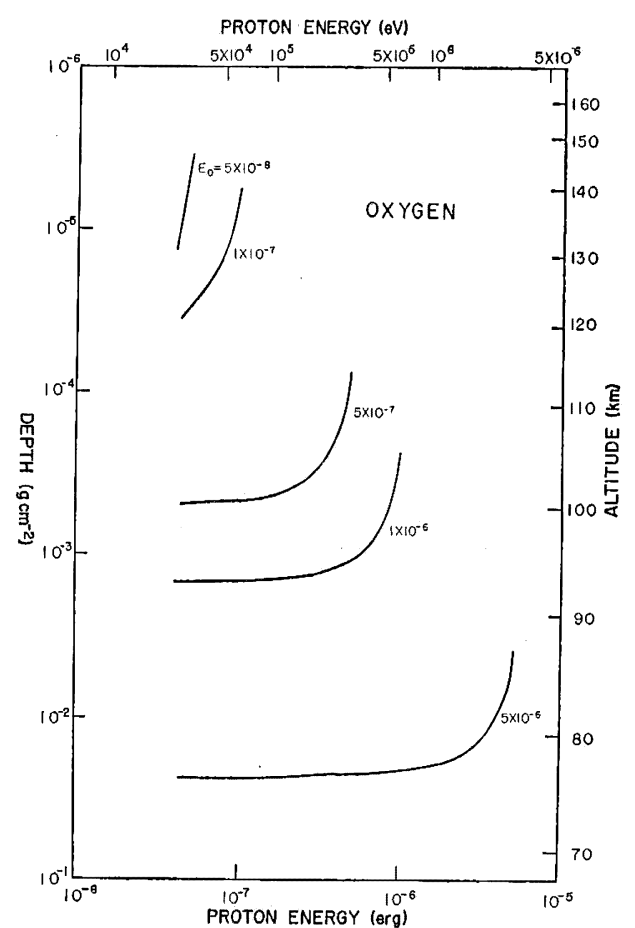

(b)

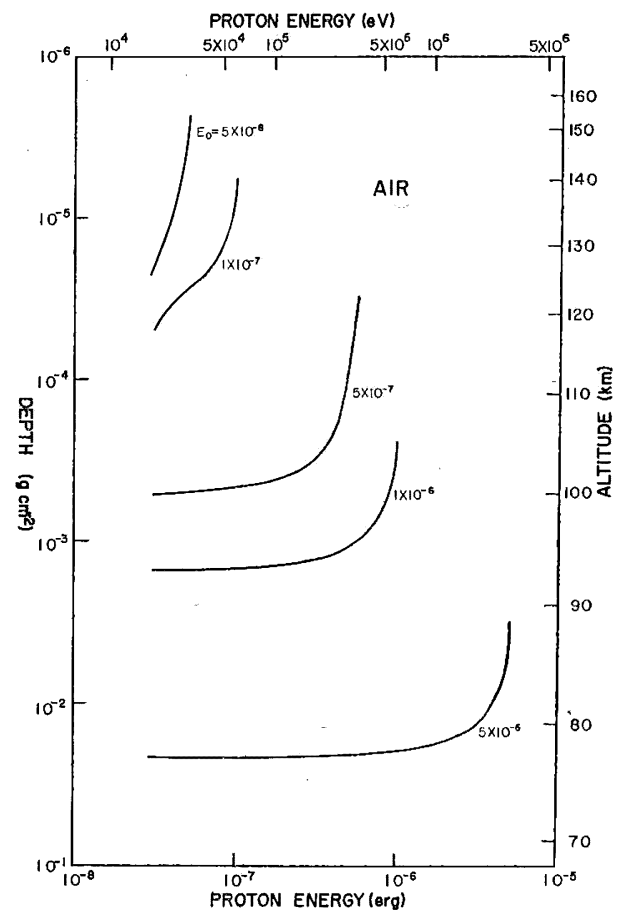

(d)

Fig. 8. Energy-depth relations of the proton primary in the individual constituents of the air. 


$$
\bar{C}_{p}(h)=\sum_{i} r_{i}(h) C_{p, i}
$$

$\gamma_{i}$ is the mixing ratio of the $i$-element in the air and is a function of the altitude, $h$.

In Fig. 9, $\bar{C}_{p}$ computed from equation (44) is shown as a function of altitude. Hence the rate of temperature increase at a certain level can be calculated by the equation.

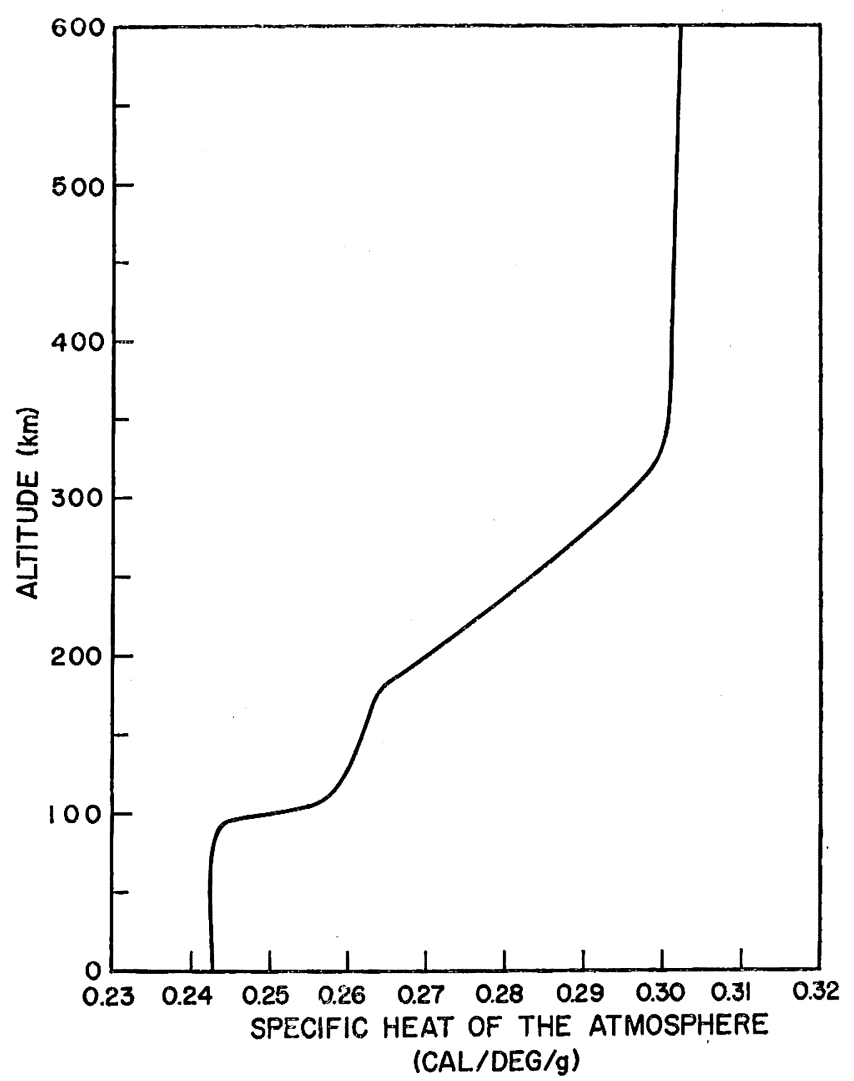

Fig. 9. Computed specific heat of the air as a function of altitude.

$$
\frac{d T}{d t}=\left(\frac{d Q}{d t}\right) / \vec{C}_{p}
$$

where $\frac{d Q}{d t}$ is related to the energy flux of corpuscular radiation, $\mathfrak{~}$,

$$
\mathfrak{F}=\int_{0}^{\infty} E_{0} \phi\left(E_{0}\right) d E_{0}
$$

by means of the equation (40).

The heat production at various heights in the atmosphere resuluting from a traversal of a charged particle was calculated by means of equation (39) for various cases of primary energy, $E_{0}$. The results obtained are shown in Figs. 10a-10h. 


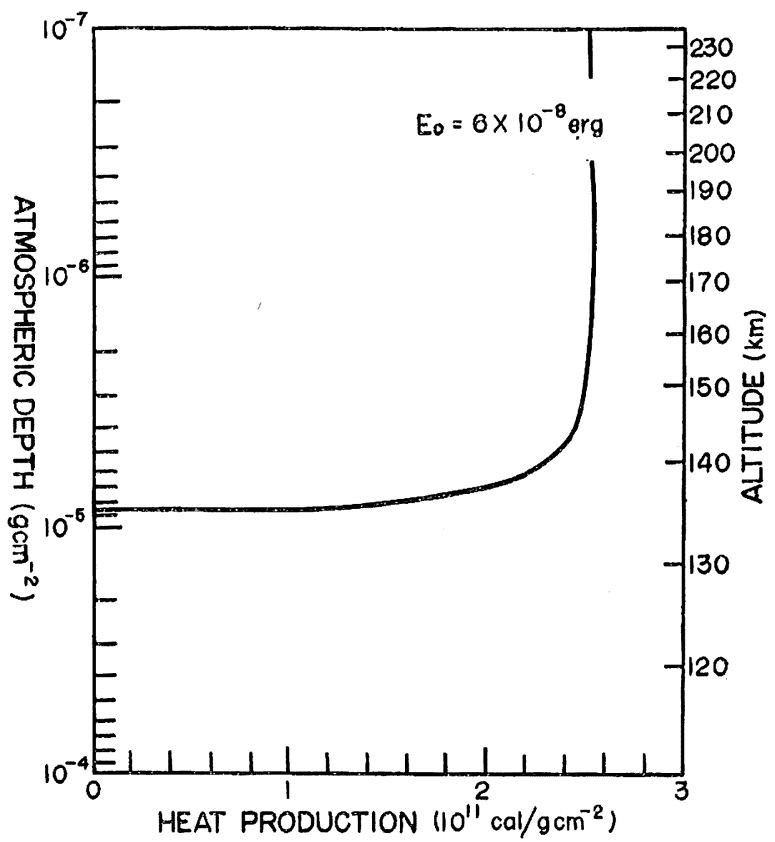

(a)

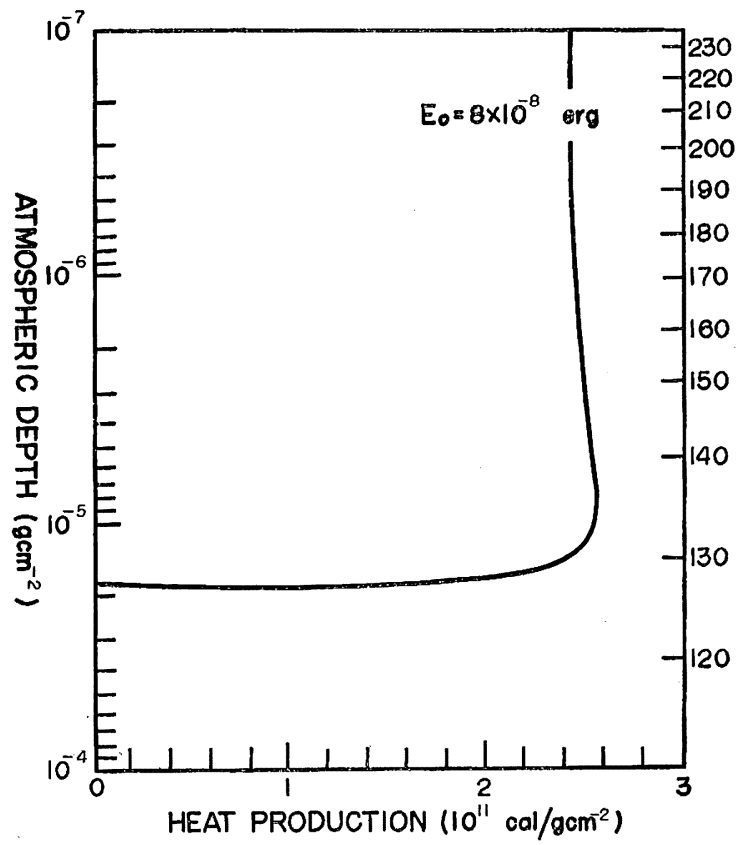

(b) 


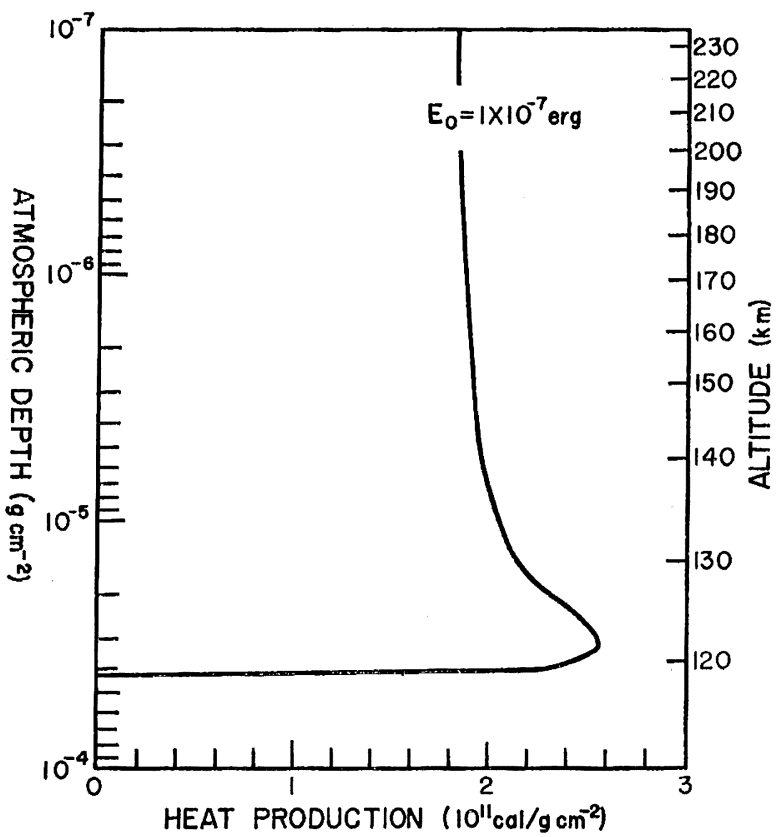

(c)

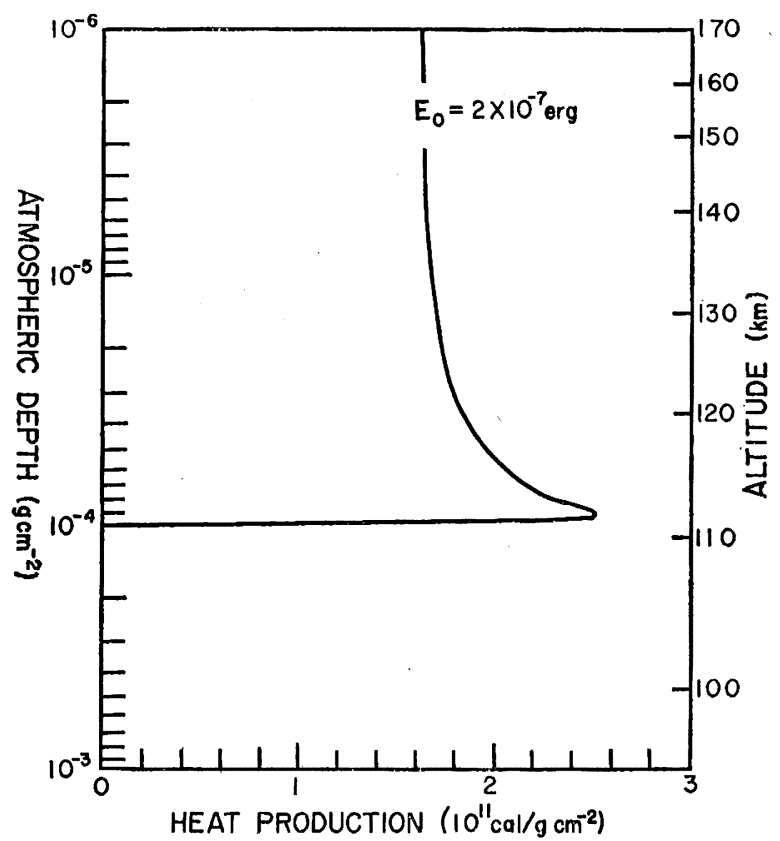

(d) 


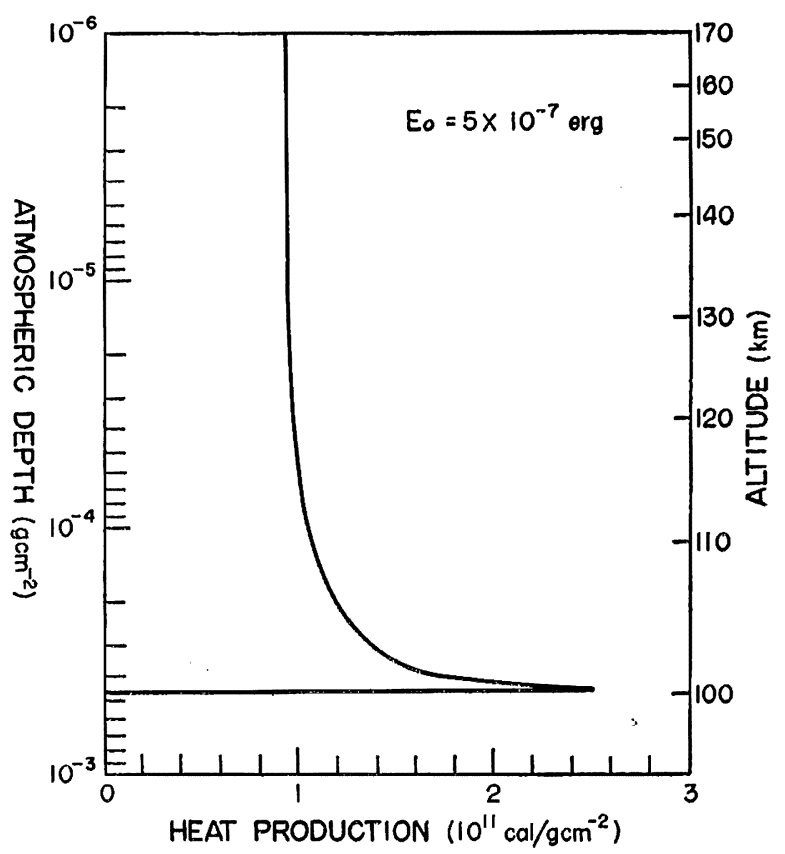

(e) 琴]

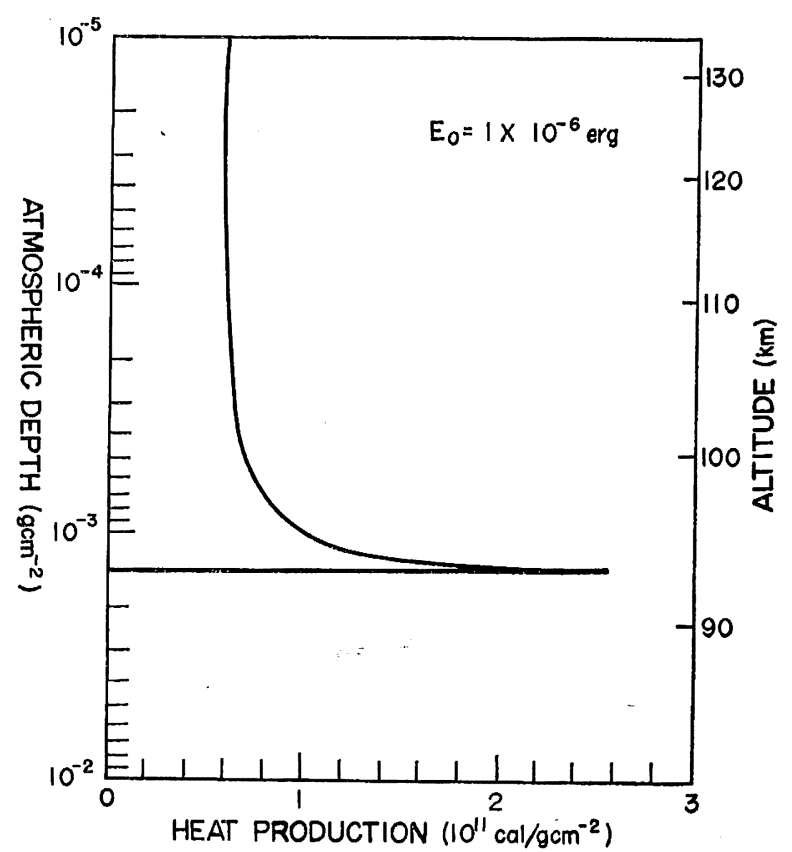




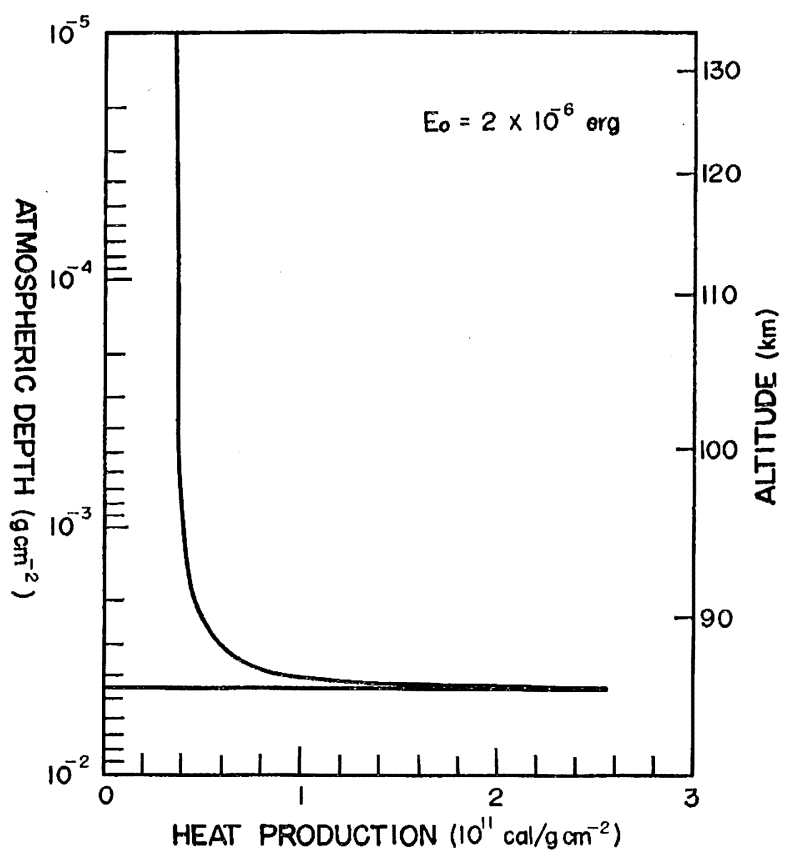

(g)

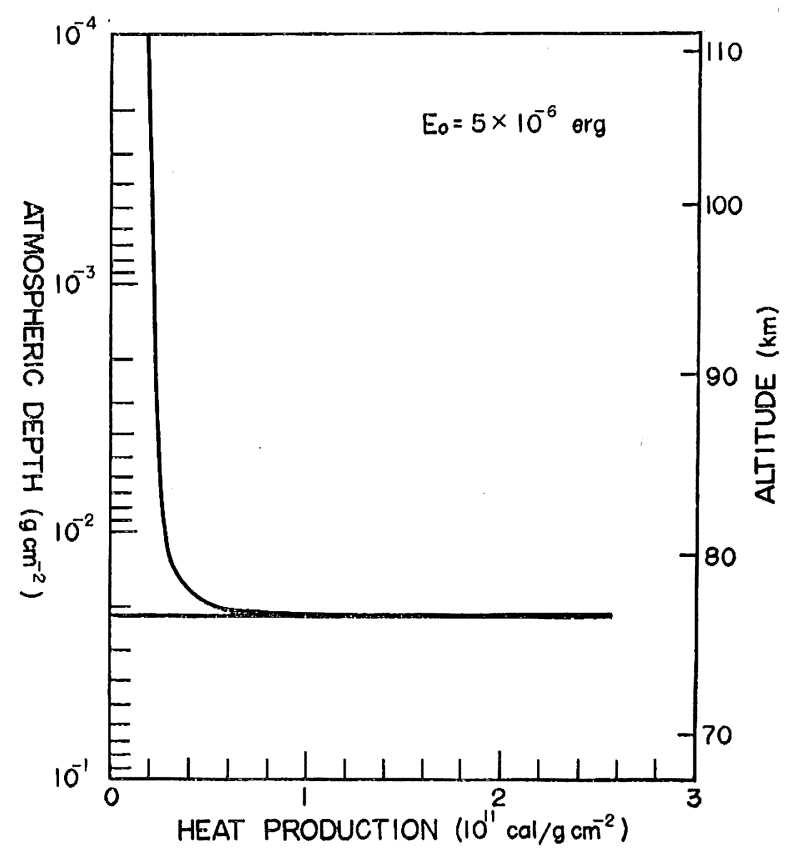

(h)

Fig. 10. The heat production at various heights in the atmosphere resulting from a traversal of a charged particle. 
The maximum heat production rate per $\mathrm{g} \mathrm{cm}^{-2}$ does not differ so much in each case in so far as the primary energy is larger than the critical energy, $E_{c}$. The height and the thickness of the atmosphere where the heat is effectively produced, however, differ in each case as shown in Figs. 11 and 12.

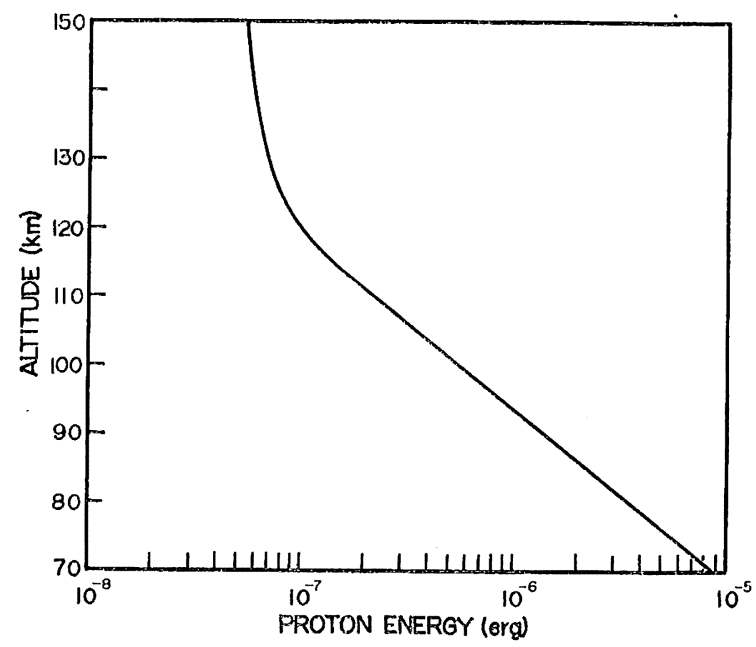

Fig. 11. The height of the atmosphere where the heat is effectively produced by passing a charged particle of various energy.

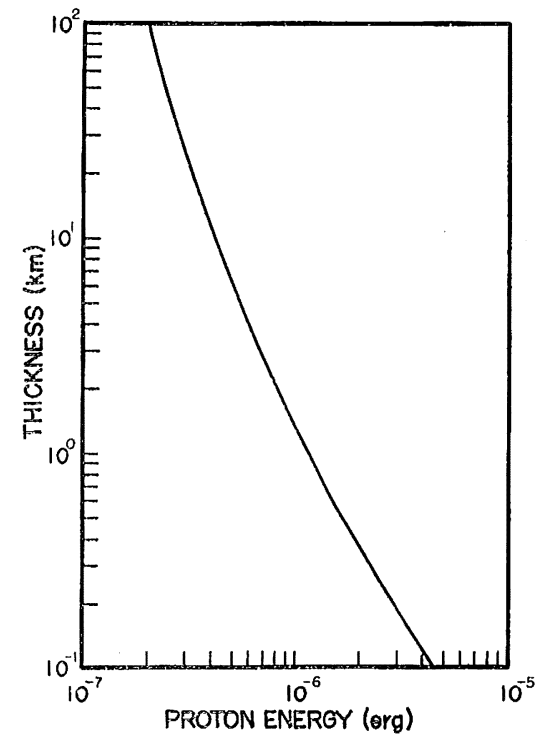

Fig. 12. The effective thickness of the atmosphere where the heat is produced by passing a charged particle of various energy.

It must be noted that the traditional way of estimating the heating rate, which simply states that the energy loss of a primary radiation passing through the atmosphere results thoroughly in heat production, is not true. As shown in the present calculation, only a little less than sixty per cent of the energy loss of the primary particle is transformed into thermal energy, and the rest is spent in electronic excitation of the atoms which will not contribute primarily to thermal condition of the atmosphere but will result in re-emission of photons. Part of the re-emitted photons might or might not be absorbed in the atmosphere depending on its wave length and on the composition of the atmosphere at a certain level concerned, and the thermal effects of those photons must be considered separately as secondary phenomena.

As is seen in equation (40), the heat production rate of the primary radiation at various levels in the atmosphere depends on the energy spectrum of the primary radiation. Our knowledge on the energy spectrum of the primary radiation seems inadequate at the present stage. CHAMBERLAIN (1957) discussed the velocity dispersion of protons that are incident on the atmosphere during auroral arcs. He suggested that the energy spectrum of auroral particles of an approximate form $E^{-1}$ could give a consistent explanation to the luminosity-curves and hydrogen-line profiles. MeREDITH et al. (1958) observed by Aerobee-Hi rockets that the energy spectrum of the ions incident on the atmosphere was variable, having in one case the form 
$\exp (-E / 72 k e v)$ and in another $\left(1 / E^{1.4}\right)$ at Ft. Churchill. O'BRIEN (1958) pointed out an interesting relation existing between the flux of auroral particles and the energy spectrum of primary cosmic rays, which suggests the existence of the energy spectrum of the auroral particles similar to that of primary cosmic rays, namely, of the form $E^{-2.5}$.

Thus the energy spectra of the corpuscular radiations are still on uncertain ground partly due to the different results of observations and because the necessary theories concerning the analysis of data are not accurately known. Hence we have considered here tentatively six different cases in assuming the energy spectrum of the primary radiation.

In our present research we assumed that the total flux of energy is a constant having the value of $5 \mathrm{erg} \mathrm{cm}^{-2} \mathrm{sec}^{-1}$. This small value for the average total flux of energy at a medium-size aurora is adopted because the recent data of rockets and satellites do not indicate the existence of much larger flux of energy like that estimated by WARWICK and that of $2 \times 10^{5} \mathrm{erg} \mathrm{cm}^{-2} \mathrm{sec}^{-1}$ which appeared in a similar discussion by LoNDON (1956)

The six different cases are as follows:

Case 1.

$$
\begin{aligned}
\phi\left(E_{0}\right) d E_{0} & =C_{1} d E_{0} & & E_{c}<E_{0}<E_{1} \\
& =0 & & \text { otherwise }
\end{aligned}
$$

where $E_{c} \sim 3 \times 10^{-8} \mathrm{erg} /$ particle.

From the equation (46) we get,

$$
5=\int_{3 \times 10^{-8}}^{E_{1}} C_{1} E_{0} d E_{0},
$$

or,

$$
\phi\left(E_{0}\right)=C_{1} \sim \frac{10}{E_{1}^{2}-9.10^{-16}} \text { particles } / \mathrm{cm}^{2} / \mathrm{sec} / \mathrm{erg}
$$

Since the energy spectrum is a flat function in a given range in this case, the energy carried by the primary radiation is concentrated near the upper limit, $E_{1}$. Hence the particle density of the primary radiation increases with $E_{1}$ decreases. Calculated $\phi\left(E_{0}\right)$ and the particle density $N / \mathrm{cm}^{3}$ with various assumed $E_{1}$ values are shown in Table 4.

Table 4.

\begin{tabular}{ccccc}
\hline \hline $\begin{array}{c}E_{1} \\
(\mathrm{erg})\end{array}$ & $\psi\left(E_{0}\right)$ & $N / \mathrm{cm}^{3}$ & $\begin{array}{c}\text { Velocity } \\
(\mathrm{cm} / \mathrm{sec})\end{array}$ & $\begin{array}{c}\text { Minimum Height } \\
(\mathrm{km})\end{array}$ \\
\hline $6 \cdot 10^{-8}$ & $2.778 \times 10^{15}$ & $6.30 \times 10^{-1}$ & $2.65 \times 10^{8}$ & 132 \\
$8 \cdot 10^{-8}$ & $1.563 \times 10^{15}$ & $4.10 \times 10^{-1}$ & $3.05 \times 10^{8}$ & 125 \\
$1 \cdot 10^{-7}$ & $1.000 \times 10^{15}$ & $2.75 \times 10^{-1}$ & $3.41 \times 10^{8}$ & 120 \\
$3 \cdot 10^{-7}$ & $1.111 \times 10^{14}$ & $5.75 \times 10^{-2}$ & $5.90 \times 10^{8}$ & 106 \\
$5 \cdot 10^{-7}$ & $4.000 \times 10^{13}$ & $2.75 \times 10^{-2}$ & $7.60 \times 10^{8}$ & 101
\end{tabular}


$1.000 \times 10^{13}$

$9.25 \times 10^{-3}$

$1.09 \times 10^{9}$

93

4. $443 \times 10^{12}$

$5.00 \times 10^{-3}$

1. $32 \times 10^{9}$

$1.53 \times 10^{9}$

1. $86 \times 10^{9}$

1. $80 \times 10^{-3}$

1. $111 \times 10^{12}$

2. $15 \times 10^{9}$

8. $25 \times 10^{-4}$

2. $42 \times 10^{9}$

89

6. $250 \times 10^{11}$

4. $000 \times 10^{11}$

Case 2.

$$
\begin{aligned}
\psi\left(E_{0}\right) d E_{0} & =\frac{C_{2}}{E_{0}} d E_{0} & & E_{c}<E_{0}<E_{1} \\
& =0 & & \text { otherwise }
\end{aligned}
$$

The energy spectrum of primary radiation in this case is an inverse function of the energy in a certain energy range which is consistent with Chamberlain's suggestion. We get from the equation (46) the expression of $C_{2}$ as,

$$
C_{2}=\frac{5}{\left(E_{1}-3 \times 10^{-8}\right)}
$$

Case 3.

$$
\begin{aligned}
\psi\left(E_{0}\right) d E_{0} & =C_{3} E_{0} d E_{0} & & E_{c}<E_{0}<E_{1} \\
& =0 & & \text { otherwise }
\end{aligned}
$$

From the equation (46), we obtain

$$
C_{3}=\frac{15}{\left(E_{1}^{3}-2.7 \times 10^{-23}\right)}
$$

Though this spectrum shape has not been actually observed, the possibility of the existence of the energy spectrum of increasing function of $E_{0}$ is not to be ignored considering the low energy region of the energy spectrum of cosmic rays.

Case 4 .

$$
\begin{aligned}
\psi\left(E_{0}\right) d E_{0} & =C_{4} E_{0}{ }^{-1.5} d E_{0} & & E_{c}<E_{0}<E_{1} \\
& =0 & & \text { otherwise }
\end{aligned}
$$

This energy spectrum coincides with one of the observed spectra by Meredith et $a l$ at Ft. Churchill. We obtain from this spectrum,

$$
C_{4}=\frac{2.5}{\sqrt{E_{1}}-\sqrt{3} \times 10^{-4}}
$$

Case 5.

$$
\begin{aligned}
\phi\left(E_{0}\right) d E_{0} & =C_{5} E_{0}{ }^{-2.5} d E_{0} & & E_{c}<E_{0}<E_{1} \\
& =0 & & \text { otherwise }
\end{aligned}
$$

This coincides with the energy spectrum of primary cosmic rays.

The constant $C_{5}$ is obtained from equation (46) as,

$$
C_{5}=\frac{2.5 \sqrt{3 E_{1}} \times 10^{-4}}{\sqrt{E_{1}}-\sqrt{3} \times 10^{-4}}
$$




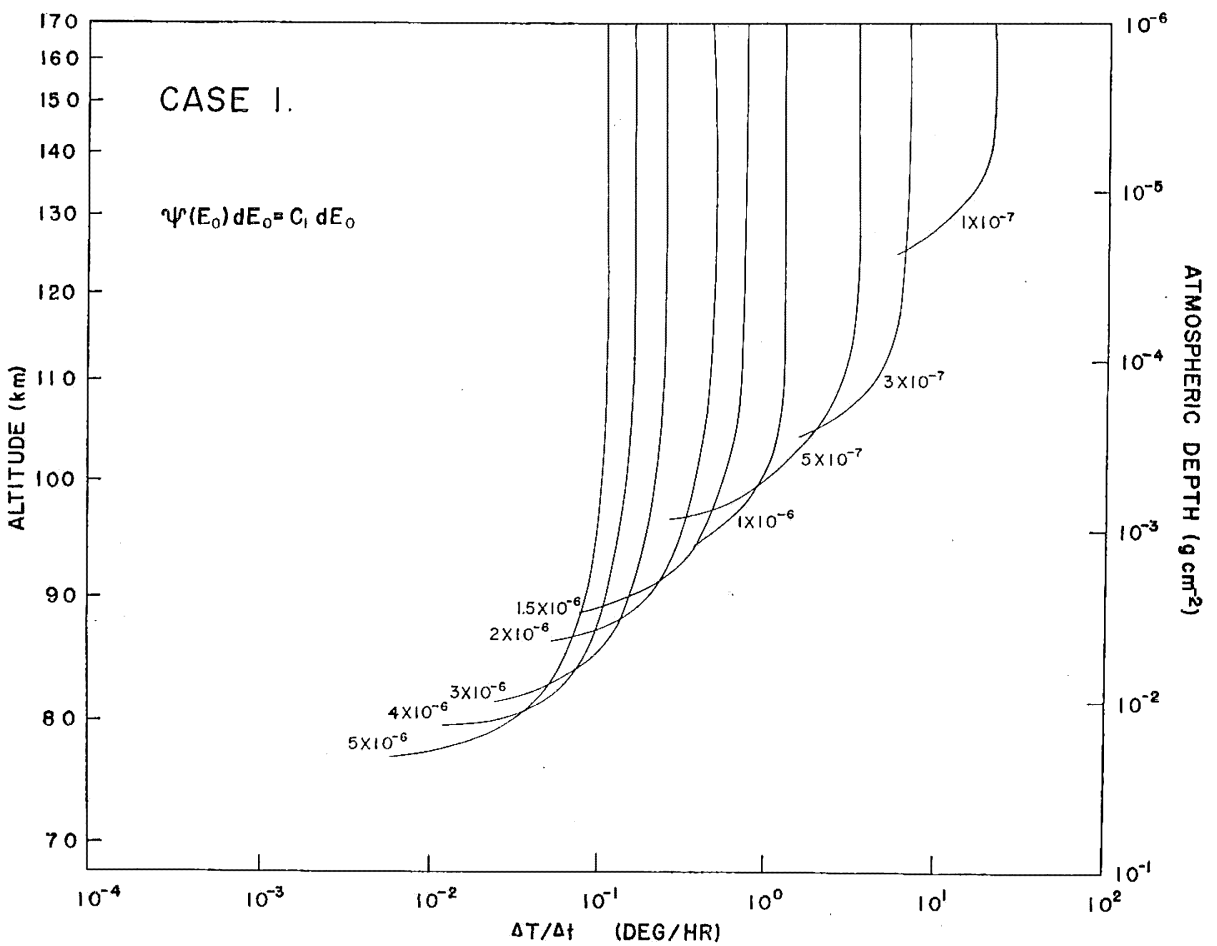

(a)

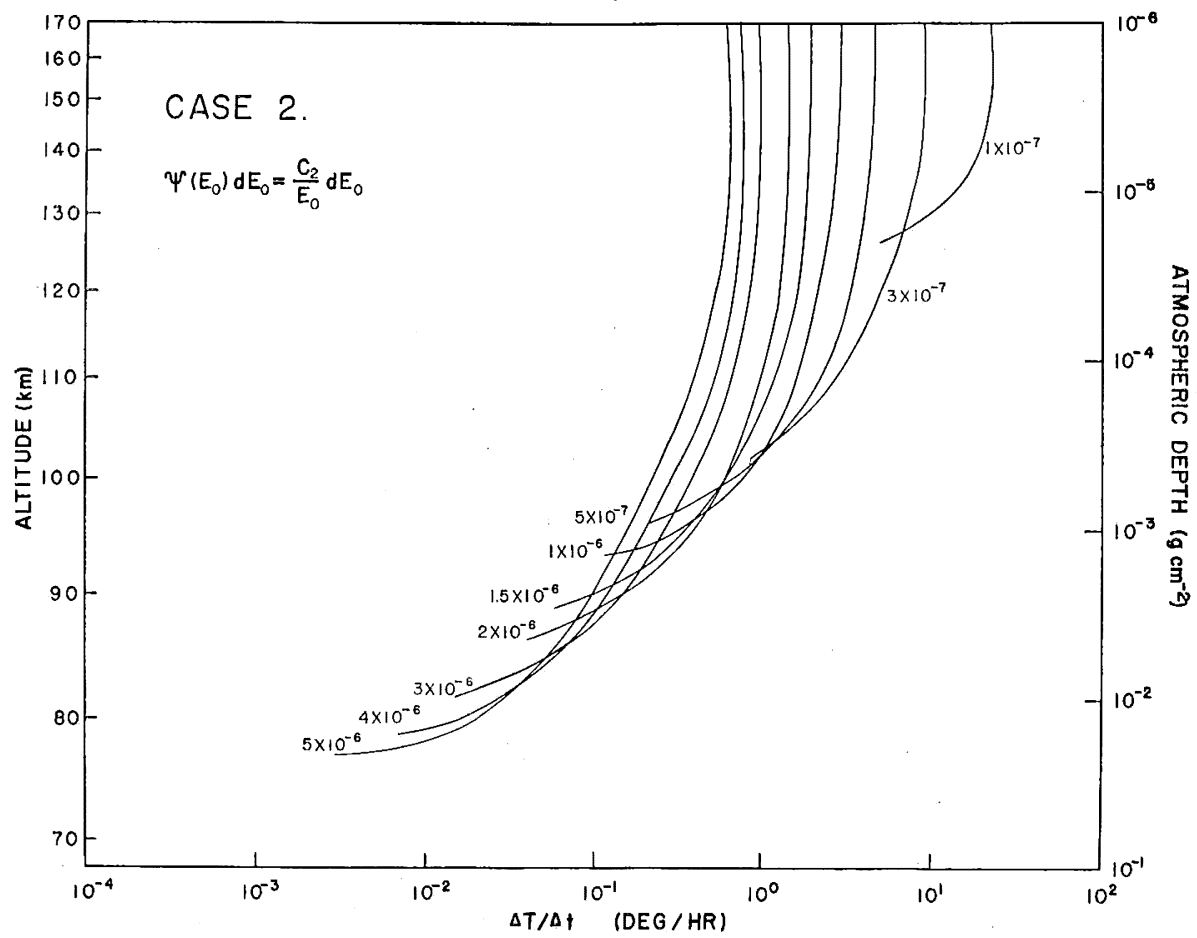

(b) 
Vol. X No. 2

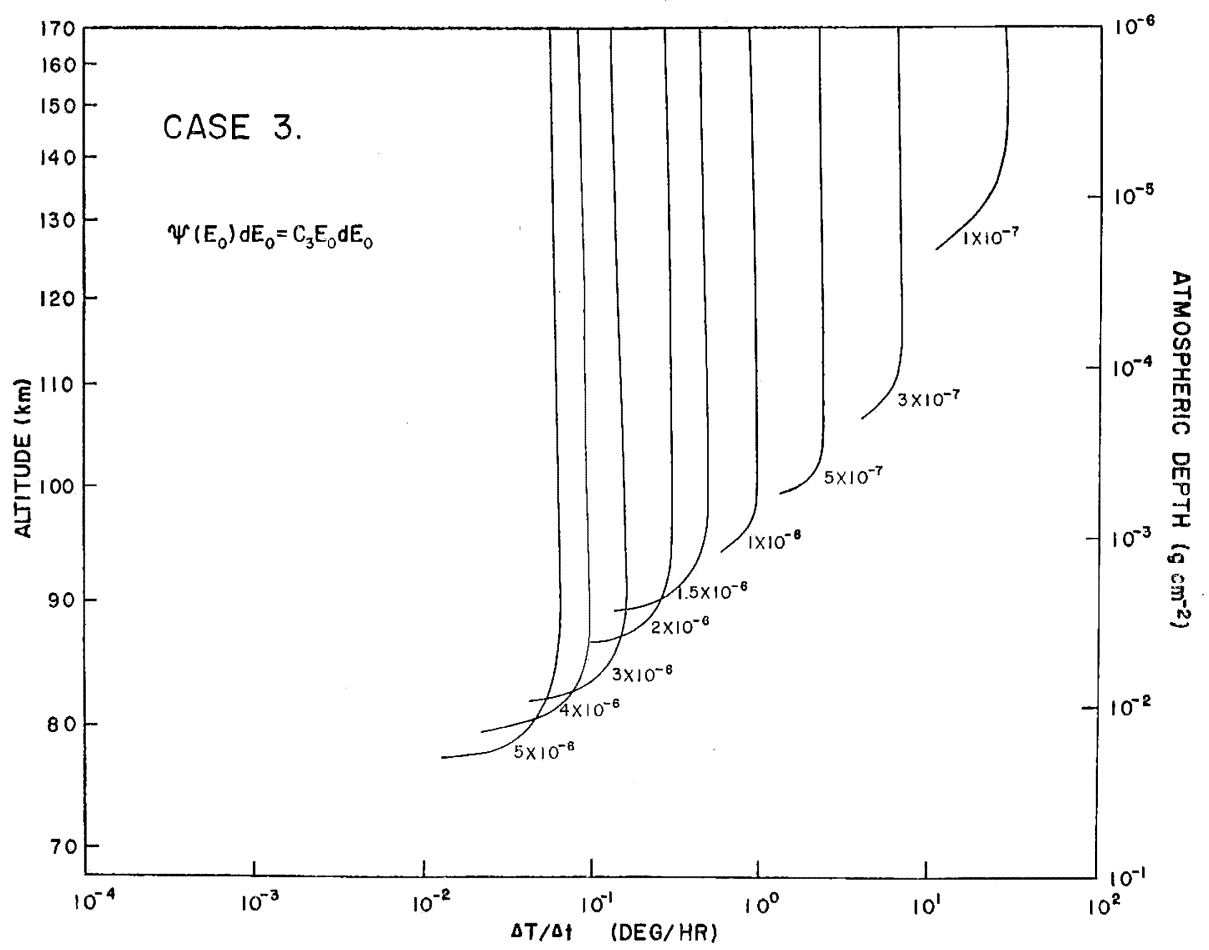

(c)

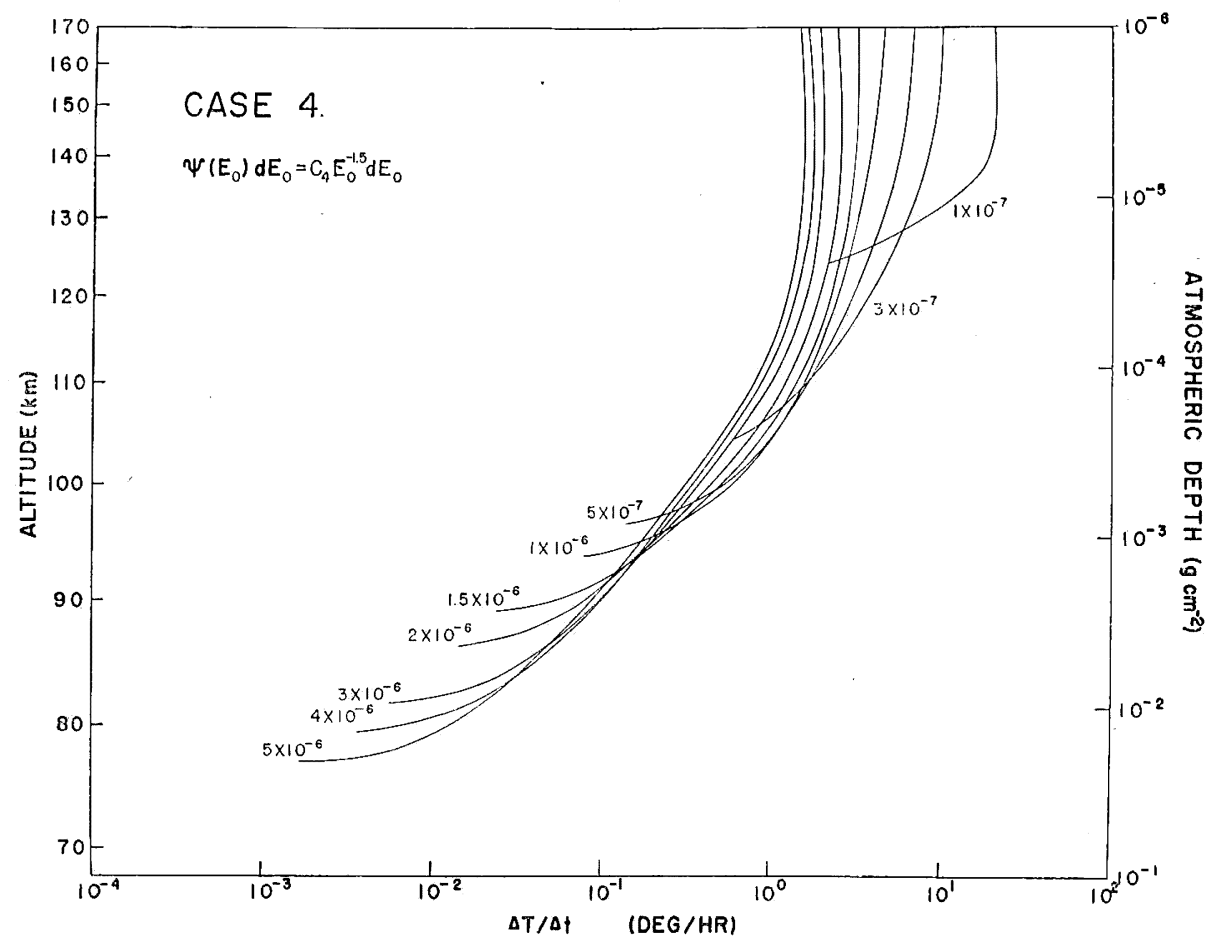

(d) 
1959 Solar Corpuscular Radiation as a Heat Source of the Upper Atmosphere

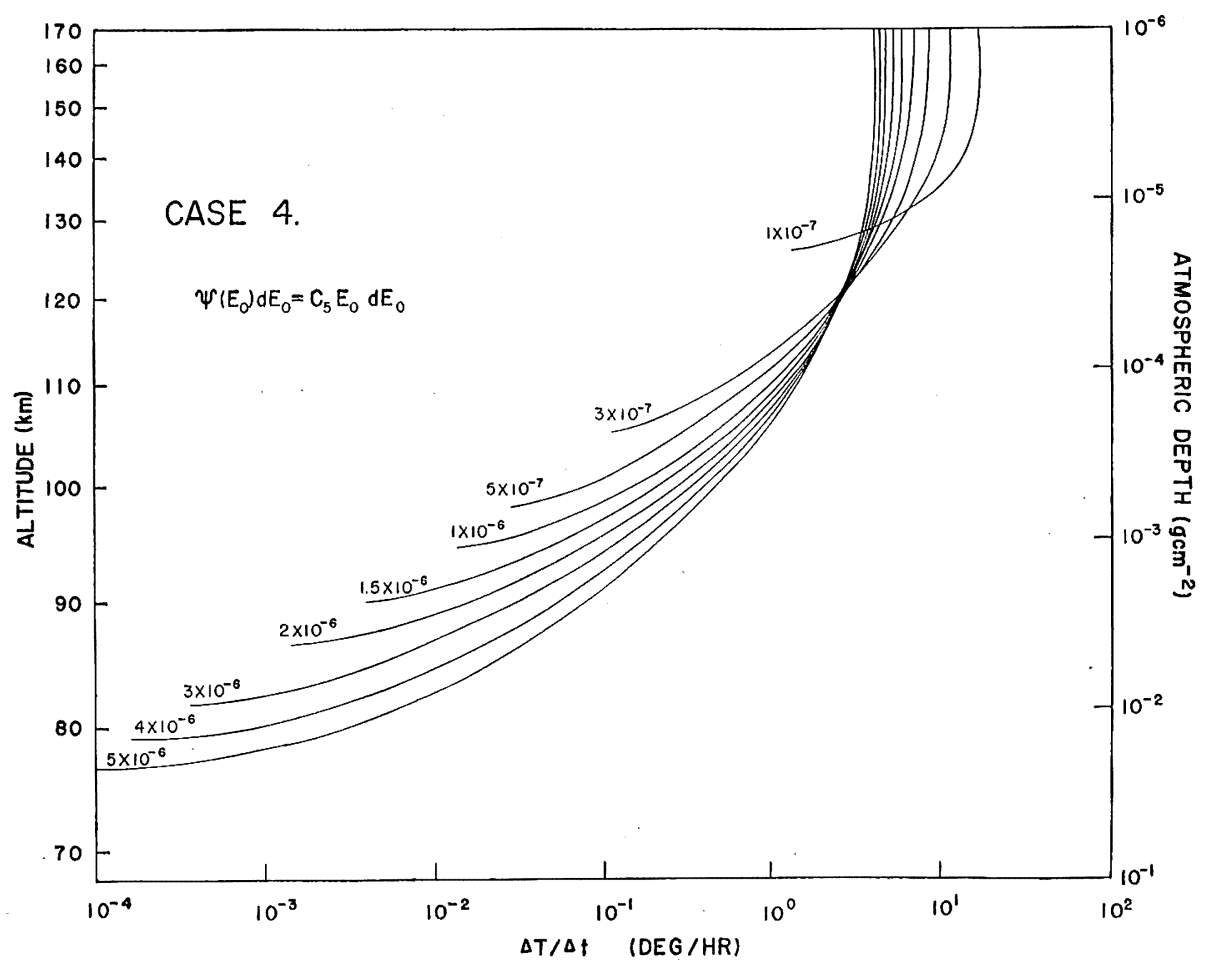

(e)

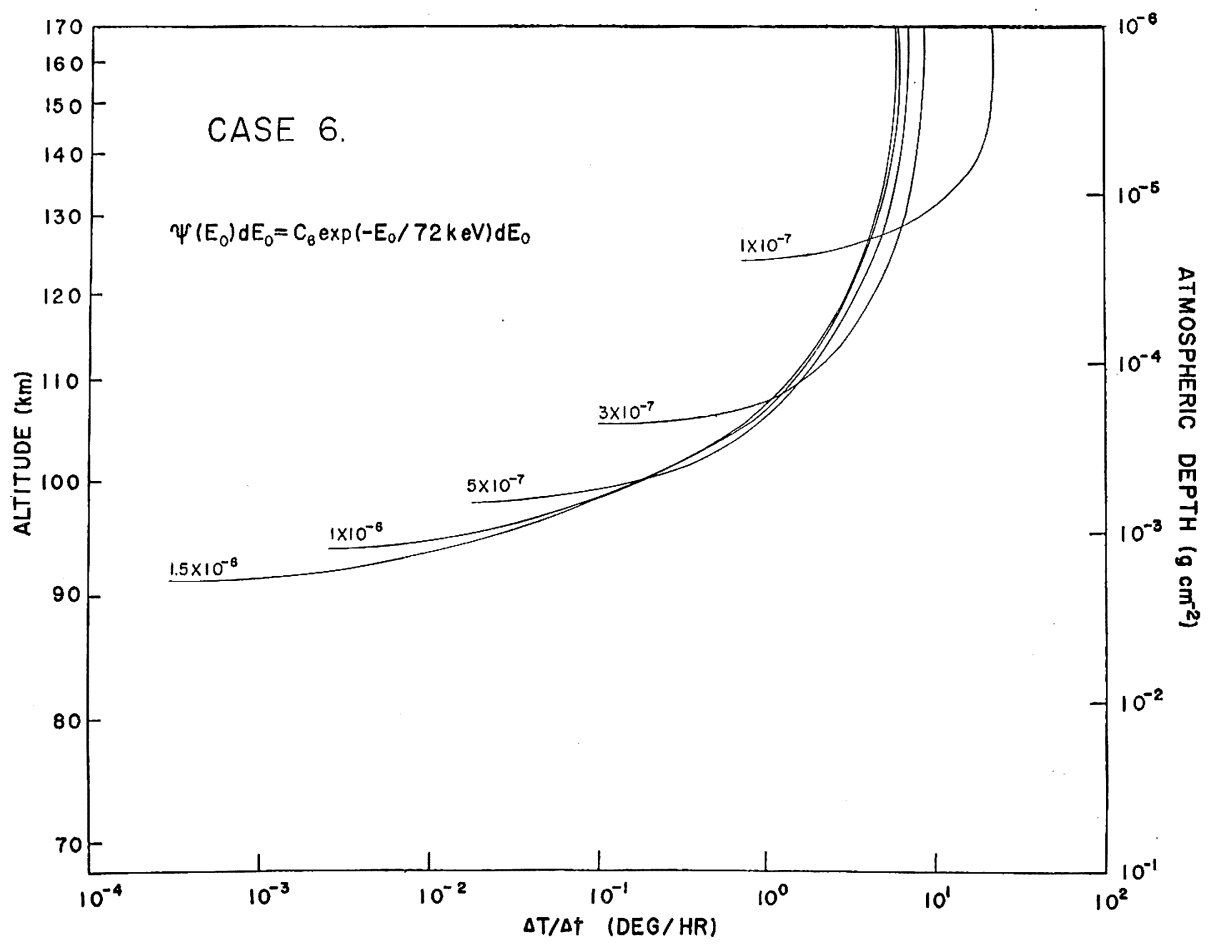

(f)

Fig. 13. The calculated rate of temperature increase in the atmosphere for various 
Case 6.

$$
\begin{aligned}
\phi\left(E_{0}\right) d E_{0} & =C_{6} \exp \left(-E_{0} / 72 \mathrm{kev}\right) d E_{0} & & E_{c}<E_{0}<E_{1} \\
& =0 & & \text { otherwise }
\end{aligned}
$$

This spectrum coincides with another one of the observed spectra by MEREDITH et al. The constant $C_{6}$ becomes,

$$
C_{6}=5\left[1.2923 \times 10^{-14}-1.1534 \times 10^{-7}\left(E_{1}+1.1534 \times 10^{-7}\right) \exp \left(-\frac{E_{1}}{1.1534 \times 10^{-7}}\right)\right]^{-1}
$$

The rate of temperature increase at various levels of the atmosphere is calculated by means of equation (45) for these six cases with various $E_{1}$ values. The results obtained are shown in Figs. 13a-13f.

Considering that the effect of the earth's magnetic field is ignored in this calculation, the above results must be applicable only for the case of vertical incidence of primary particles at very near the auroral region.

\section{References}

Notes from cross-field seminar on possible responses of terrestrial atmospheric circulation to changes in solar activity, compiled by P. JuJian et al., 1956 (See especially J. W. WARWICk's and W. O. RoBerts' chapters)

Alfren, H., 1939: Theory of magnetic storms, I. Kungle. Sv. Vet.-Akademiens Handl. (3), 18, No. 3.

Alfven, H., 1940: Theory of magnetic storms, II, III. Kungle. Sv. Vet.-Akademiens Handl. (3), 18, No. 9.

Alffen, H., 1947: Solar magnetic field and diurnal variation of cosmic ray radiation, Phys. Rev. 72, 88-89.

Alfven, H., 1955: On the electric field theory of magnetic storms and aurorae. Tellus, 7, 50-64.

Bennett, W.H., and E. Hulbert, 1954: Theory of the aurora based on magnetic self-focusing of solar ion streams. Phys. Rev. 95, 315-319.

Bennetw, W.H., 1955 : Self-focusing streams. Phys. Rev. 98, 1584-1593.

Bennetr, W.H., 1958: Auroral and magnetic-storm theory. Astrophys J. 127, 731-742.

BenNerr, W.H.. 1959: Solar proton stream forms with a laboratory model. Rev. Sci. Instr. 30, 63-69.

Chamberlatin, J.W., 1957: On a possible velocity dispersion of auroral protons. Astrophys. J. 126, 245-252.

Chapman, S. and V.C.A. Ferraro, 1932: A new theory of magnetic storms. Terr. Mag. Atm. Elec., 36, 77-97 and 171-186.

Chapman, S. and V.C.A. Ferraro, 1932: A new theory of magnetic storms. Terr. Mag. Atm. Elec., 37, 147-156 and 421-429.

Chapman, S. and V.C.A. Fegrraro, 1933: A new theory of magnetic storms. Terr. Mag. Atm. Elec., 38, 79-96.

Chapman, S., 1954: Corpuscular influences upon the upper atmosphere. J.G.R. 55, 361-372.

Cook, C.J., E. Jones, and J. JoRgensen, 1953: Range-energy relations of 10 to $250-\mathrm{kev}$ protons and helium ions in various gases. Phys. Rev. 91, 1417-1422.

Craig, R.A. and G. Ohring, 1958: The temperature dependence of ozone radiational heating rates in the vicinity of the mesopeak. J. Met. 15, 59-62. 
Kiepenheuer, K.O., 1954: Emission of corpuscles from the sun. Geophys. Res. Pap. No. 30, AFCRC, 403-413.

LANDSEER-Jones, B.C., 1952: The streaming of charged particles through a magnetic field as a theory of the aurora. J.A.T.P. 3, 41-57.

LANDSEer-Jones, B.C., 1955: The significance of a non-terrestrial magnetic field in neutral stream theories of the aurora. J.A.T.P. 6, 215-226.

London, J., 1956: The radiation budget of the troposphere and stratosphere. Note from Cross-field Seminar.

MARTYN, D.F., 1951: The theory of magnetic storms and auroras. Nature, 167, 92-94.

MeineL, A.B., 1951: Doppler-shifted auroral hydrogen emission. Astrophys. J. 113, 50-54.

Meredith, L.H., L.R. Davis, J.P. Heppner, and O.E. Berg, 1958 : Rocket auroral investigations, Experimental results of the U.S. rocket program for the IGY to 1 July 1958, 169-178.

MILLER, L.E., 1957: "Molecular weight" of air at high altitudes. J. G. R., 62, 351-365.

O'Brien, B.J., 1958: Energy spectrum of particles bombarding the earth. Nature, 182, 521.

Pecker, J.C. and W. O. Roberts, 1955: Solar corpuscles responsible for geomagnetic disturbances. J.G.R. 60, 33-44.

Schiliting, G.F. and T.E., Sterne, 1959: Densities and temperatures of the upper atmosphere inferred from satellite observations. J.G.R. 64, 1-4.

Singer, S.F., 1957: A new model of magnetic storms and aurorae. Trans. Amer. Geophys. Union. 38, 175-190.

Treiman, S.B., 1953 : The cosmic-ray albedo. Phys. Rev., 91, 957-959.

Van Allen, J. A., G. H. Ludwis, E. C. Ray, and C. E. Molluwain, 1958: Observation of high intensity radiation by satellites $1958 \alpha$ and $\gamma$. Jet Propulsion, 28, 588-592.

VAN Allen, J.A., C.E. Mcllwain, and G.H. Lodwig, 1959: Radiation observations with satellite 1958 \&. J.G.R. 64, 271-286.

\title{
高層大気熱源としての太陽微粒子輻射
}

\author{
石川業六
}

微粒子輻射が地球大気に入射した場合の熱発生を論ずる。大気棈成原子と微粒子輻射との衝突による電

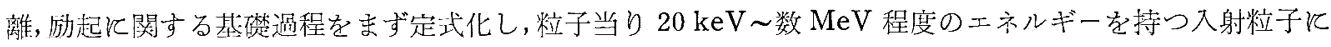
ついての，エネルギ一損失, 熱発生, エネルギ一分散等を算出した。大気の構成については L.E. MILLERの モデルを用い，微椟子輻射強度及びそのエネルギースペクトルルついては最近のロケット钼測結果を用い た。微粒子輻射による熱発生はそのエネルギ一損失の約 $60 \%$ 程度が第1次の熱発生として有効であり,残余 は光子の再㬏射等の 2 次的過程として論ぜられるべきである。従来の微粒子輻射強度が $>10^{4} \mathrm{erg} / \mathrm{cm}^{2} / \mathrm{sec}$ という值は過大評洒であり，中等度の極光生起侍江於いても数〜数 $10 \mathrm{erg} / \mathrm{cm}^{2} / \mathrm{sec}$ 程度の入射強度と考 えられる。しかしこの場合でも極光帯附近での発熱量は大きく，またとの垂直方向の分枊は，大射粒子の エネルギースペクトルに著しく左右される。ロケット観测や宇宙線観测から推定される太陽微粒子輻射の エネルギースペクトルは一定して括らず，ここでは 6 種類のエネルギースペクトルを仮定して，その各々 の場合についての熱発生を $70 \mathrm{~km}$ 以上の大気について計算した。計算結果は将来一次輻射の観测がより正 確に得られた場合有效に用いられるように, 各種のパラメータルついて为表が作られている。 